OPEN ACCESS

Edited by:

John P. Carr,

University of Cambridge,

United Kingdom

Reviewed by:

Anna Maria Vaira,

Istituto per la Protezione Sostenibile

Delle Piante (IPSP), Italy Miroslav Glasa,

Slovak Academy of Sciences, Slovakia

*Correspondence:

Miguel A. Aranda

m.aranda@cebas.csic.es

Specialty section: This article was submitted to Virology,

a section of the journal

Frontiers in Microbiology

Received: 11 October 2018 Accepted: 10 December 2018 Published: 21 December 2018

Citation:

Bernal-Vicente A, Donaire L, Torre C, Gómez-Aix C, Sánchez-Pina MA,

Juarez $M$, Hernando $Y$ and Aranda MA (2018) Small RNA-Seq to Characterize Viruses Responsible of Lettuce Big Vein Disease in Spain. Front. Microbiol. 9:3188. doi: 10.3389/fmich.2018.03188

\section{Small RNA-Seq to Characterize Viruses Responsible of Lettuce Big Vein Disease in Spain}

\author{
Agustina Bernal-Vicente ${ }^{1}$, Livia Donaire ${ }^{2}$, Covadonga Torre ${ }^{1}$, Cristina Gómez-Aix ${ }^{1}$, \\ Maria Amelia Sánchez-Pina ${ }^{2}$, Miguel Juarez ${ }^{3}$, Yolanda Hernando ${ }^{1}$ and Miguel A. Aranda ${ }^{2 \star}$ \\ ${ }^{1}$ Department of Research and Development, ABIOPEP S. L., Murcia, Spain, ${ }^{2}$ Biology of Stress and Plant Pathology \\ Department, CEBAS-CSIC, Murcia, Spain, ${ }^{3}$ Plant Production and Microbiology Department, University Miguel Hernández of \\ Elche, Orihuela, Spain
}

The emerging lettuce big-vein disease (LBVD) is causing losses in lettuce production ranging from 30 to $70 \%$ worldwide. Several studies have associated this disease with Mirafiori lettuce big-vein virus (MiLBW) alone or in mixed infection with lettuce big-vein associated virus (LBVaV). We used Illumina small RNA sequencing (sRNA-seq) to identify viruses present in symptomatic lettuce plants from commercial fields in Southern Spain. Data analysis using the VirusDetect tool showed the consistent presence of MiLBW and LBVaV in diseased plants. Populations of MiLBW and LBVaV viral small RNAs (sRNAs) were characterized, showing features essentially similar to those of other viruses, with the peculiarity of an uneven asymmetric distribution of MiLBV virus-derived small RNAs (vsRNAs) for the different polarities of genomic RNA4 vs. RNAs1 to 3. Sanger sequencing of coat protein genes was used to study MiLBV and LBVaV phylogenetic relationships and population genetics. The Spanish MiLBWV population was composed of isolates from three well-differentiated lineages and reflected almost all of the diversity reported for the MiLBW species, whereas the LBVaV population showed very little genetic differentiation at the regional scale but lineage differentiation at a global geographical scale. Universal primers were used to detect and quantify the accumulation of MiLBV and LBVaV in field samples; both symptomatic and asymptomatic plants from affected fields carried equal viral loads, with LBVaV accumulating at higher levels than MiLBWV.

Keywords: lettuce, LBVaV, MiLBVV, big-vein disease, small RNA-seq, qRT-PCR

\section{INTRODUCTION}

Lettuce big-vein is a damaging disease responsible for important quality and yield losses worldwide. Affected lettuce plants show chlorophyll clearing along the veins, causing a characteristic big-vein appearance, and also crinkled leaves, head size reduction and significant reduction of the quality of the edible product (Maccarone, 2013). Lettuce is increasingly cultivated all over the world due to, among other factors, the demand for fresh and healthy vegetable products, the diversification of varietal types and the expansion of the commercialization of ready-to-eat products. Lettuce big-vein disease (LBVD) can cause production losses of up to $70 \%$ in certain regions, and incidences close to $100 \%$ are frequent during the winter and early spring in specific areas of cultivation 
(Moreno and Fereres, 2012; Maccarone, 2013; our unpublished observations). The disease was first reported in California (USA) a long time ago (Jagger and Chandler, 1934), but today the biology of the microorganisms responsible for the disease is still not fully understood. For a long time, it was thought that lettuce big-vein associated virus (LBVaV; species Lettuce big-vein associated virus, genus Varicosavirus) was the LBVD causal agent (Kuwata et al., 1983). LBVaV is a bipartite, negative-sense, single-stranded (ss) RNA virus. The viral genome has seven open reading frames (ORFs) distributed into two ssRNAs, with a coat protein $(\mathrm{CP})$ of $48 \mathrm{kDa}$ encoded by RNA2 (Sasaya et al., 2002, 2004; King et al., 2012). Later, Roggero et al. (2000) isolated a filamentous virus, Mirafiori lettuce big-vein virus (MiLBVV; species Mirafiori lettuce bigvein virus, genus Ophiovirus) from symptomatic lettuce plants and proposed that MiLBVV, but not LBVaV, was the causal agent of LBVD, as plants infected with LBVaV did not develop symptoms in the absence of MiLBVV, whereas plants infected with MiLBVV developed big-vein symptoms regardless of the presence or absence of LBVaV (Lot et al., 2002; Sasaya et al., 2008). MiLBVV is a segmented negative-stranded RNA virus. The viral genome consists of four ssRNAs containing seven ORFs. RNA3 encodes a $48.5 \mathrm{kDa}$ protein, which is the CP and a major component of its thin and filamentous particles (King et al., 2012). However, relatively recent data in the literature still questioned the LBVD etiology, as plants diagnosed positive for LBVaV but negative for MiLBVV by ELISA were symptomatic at least in a field experiment in Italy (Roggero et al., 2003); differential sensitivity of the detection method used for each virus may underlie this conflicting observation. Both viruses are transmitted by zoospores of a chytridiomycete fungus, Olpidium virulentus, a soil-borne obligate root parasite (Hartwright et al., 2010; Maccarone et al., 2010a). Resting spores can remain dormant in the soil and MiLBVV or LBVaV can survive up to 20 years inside them (Campbell, 1985). For this reason, inoculum of both viruses may last for years making LBVD control a challenge once the fungus is established in the field. Control strategies are also difficult, as $O$. virulentus infects a wide range of weed species which can act as reservoirs (Campbell and Fry, 1966; Navarro et al., 2005). Maccarone (2009) has detected the presence of MiLBVV and LBVaV in extracts of seeds collected from plants infected by both viruses, so seed transmission of these viruses is possible (Maccarone, 2009).

Spain is the fourth-largest lettuce producer in the world after China, the USA and India, and it is the number one exporter worldwide ${ }^{1}$. The area of lettuce cultivation in Spain is around 34,500 ha, with 15,630 ha ( $45.3 \%$ of the total) located in the Region of Murcia (Southeast Spain), followed by Almeria (20.8\%) and Alicante (3.3\%), with Murcia being the producer of $\sim 70 \%$ of the Spanish exported lettuce ${ }^{2}$. MiLBVV and LBVaV detection has not been performed for the most comprehensive survey

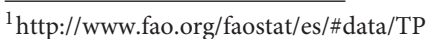

${ }^{2} \mathrm{https} / /$ www.mapama.gob.es/es/estadistica/temas/estadisticas-agrarias/ agricultura/esyrce/
}

carried out in lettuce crops in Spain (Moreno et al., 2004), but the high proportion of negative detections for the viruses tested on samples from symptomatic plants in that survey, together with additional evidence (Navarro et al., 2004, 2005) suggest that the incidence of LBVD viruses in Spanish crops is high. ELISA and RNA hybridization-based methods have been set up for the detection of both viruses (Roggero et al., 2003; Navarro et al., 2004; Sasaya et al., 2008), as well as primers and probes for virus detection by reverse transcription-real time quantitative PCR (qRT-PCR) (Momonoi et al., 2015). Previously, the genetic variability of both viruses in Spain was studied based on the sequences of the CP genes of 7 and 11 MiLBVV and LBVaV Spanish isolates, respectively, in comparison with other isolates from around the world, suggesting more diverse populations for MiLBVV than for LBVaV (Navarro et al., 2005). The aim of our study was to use deep sequencing of small RNAs (sRNAseq), a non-biased method, for identifying viruses infecting field plants affected by LBVD, and with this information, to develop techniques for the detection and characterization of the viruses present in field lettuce plants affected with LBVD and in commercial seed lots. We have also used the genetic information gathered to revisit the genetic variability and evolution of Spanish MiLBVV and LBVaV populations.

\section{MATERIALS AND METHODS Plant Material and RNA Extraction}

Lettuce crops in open fields near Águilas (Murcia, Southeast Spain) were surveyed during 2016, 2017, and 2018. For sRNA-seq and CP ORFs cloning and sequencing, three lettuce plants with LBVD-like symptoms were randomly taken from 4 different plots, and leaves and roots from these plants were sampled (Table 1). Plots ranged in size approximately between 2 and 6 ha; a single cultivar was predominantly planted in each plot and thus samples from each plot are from distinct cultivars: cv. Chavela (Enza Zaden) for plot "La Perla" (plot 1), cv. Zoliva (Nunhems) for plot "JB3" (plot 2), cv. Juanola (Enza Zaden) for plot "Primicias" (plot 3), and cv. Fernandola (Enza Zaden) for plot "La Serreta" (plot 4). Total RNA from roots and leaves was purified using TRI Reagent following the manufacturer's instructions (Sigma-Aldrich, USA). The concentration of total RNA was determined using a NanoDrop spectrophotometer (Thermo Fisher Scientific, USA) and its quality was checked with agarose gel electrophoresis.

For the detection and analysis of distribution of MiLBVV and LBVaV in leaves and roots, 26 lettuce plants from additional plots in Águilas were sampled during winter 2017. Of the 26 iceberg lettuce plants sampled, 14 showed no symptoms, even though LBVD-like symptoms were highly prevalent $(\sim 50 \%)$ in the surveyed plots. One hundred $\mathrm{mg}$ of tissue were taken from roots, as well as from young and old leaves from each lettuce plant sampled. Additionally, seeds from 11 different lettuce varieties from 5 commercial brands were analyzed. For each of the varieties, two samples of 30 seeds each were used. Seed pellets were taken out before RNA extraction 
TABLE 1 | Samples used for sequencing in this study and cDNA clones obtained from these samples.

\begin{tabular}{|c|c|c|c|c|c|}
\hline Samples ${ }^{a}$ & $\begin{array}{l}\text { Analysis in which these } \\
\text { samples have been used }\end{array}$ & $\begin{array}{l}\text { cDNA clones for MiLBVV } \\
\text { from samples }\end{array}$ & $\begin{array}{l}\text { cDNA clones for } \\
\text { LBVaV from samples }\end{array}$ & $\begin{array}{l}\text { cDNA clones for } \\
\text { MiLBVV from poolb }\end{array}$ & $\begin{array}{l}\text { cDNA clones for } \\
\text { LBVaV from pool }\end{array}$ \\
\hline $\begin{array}{l}\text { 16_AG_1_L_1 } \\
\text { 16_AG_1_L_2 } \\
\text { 16_AG_1_R_2 } \\
\text { 16_AG_1_R_3 }\end{array}$ & $\begin{array}{l}\text { RNA-seq, pool } 1^{\mathrm{b}} \\
\text { Phylogenetic analysis }\end{array}$ & & & $\begin{array}{l}\text { Pool 1_M.1 Pool 1_M.2 } \\
\text { Pool 1_M.3 Pool 1_M.4 }\end{array}$ & $\begin{array}{l}\text { Pool 1_L.1 Pool 1_L.2 } \\
\text { Pool 1_L.3 Pool 1_L.4 }\end{array}$ \\
\hline $\begin{array}{l}\text { 16_AG_2_L_1 } \\
\text { 16_AG_2_R_1 } \\
\text { 16_AG_2_R_2 } \\
\text { 16_AG_2_L_3 } \\
\text { 16_AG_2_R_3 }\end{array}$ & $\begin{array}{l}\text { RNA-seq, pool } 2^{\mathrm{b}} \\
\text { Phylogenetic analysis }\end{array}$ & $\begin{array}{l}\text { 16_AG_2_R_3_M.1 } \\
\text { 16_AG_2_R_3_M.2 } \\
\text { 16_AG_2_R_3_M.3 } \\
\text { 16_AG_2_R_3_M.4 }\end{array}$ & $\begin{array}{l}\text { 16_AG_2_R_3_L. } 1^{C} \\
\text { 16_AG_2_R_3_L.2 } \\
\text { 16_AG_2_R_3_L.3 } \\
\text { 16_AG_2_R_3_L.4 }\end{array}$ & $\begin{array}{l}\text { Pool 2_M.1 Pool 2_M.2 } \\
\text { Pool 2_M.3 Pool 2_M.4 }\end{array}$ & $\begin{array}{l}\text { Pool 2_L.1 Pool 2v_L.29 } \\
\text { Pool 2_L.3 Pool 2_L.49 }\end{array}$ \\
\hline 17_AG_4_L_1 & Phylogenetic analysis & $\begin{array}{l}\text { 17_AG_4_L_1_M.1 } \\
\text { 17_AG_4_L_1_M.2 } \\
\text { 17_AG_4_L_1_M.3 } \\
\text { 17_AG_4_L_1_M.4 }\end{array}$ & $\begin{array}{l}\text { 17_AG_4_L_1_L.1 } \\
\text { 17_AG_4_L_1_L.2 } \\
\text { 17_AG_4_L_1_L.3 } \\
\text { 17_AG_4_L_1_L.4 }\end{array}$ & & \\
\hline 18_AG_4_L_1 & Phylogenetic analysis & $\begin{array}{l}\text { 18_AG_4_L_1_M.1 } \\
\text { 18_AG_4_L_1_M.2 } \\
\text { 18_AG_4_L_1_M.3 }\end{array}$ & $\begin{array}{l}\text { 18_AG_4_L_1_L.1 } \\
\text { 18_AG_4_L_1_L.2 } \\
\text { 18_AG_4_L_1_L.3 } \\
\text { 18_AG_4_L_1_L.4 }\end{array}$ & & \\
\hline 17_AG_Ø_S1_Ø & $\begin{array}{l}\text { Detection } \\
\text { Phylogenetic analysis }\end{array}$ & & 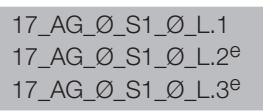 & & \\
\hline 17_AG_Ø_S4_ø & $\begin{array}{l}\text { Detection } \\
\text { Phylogenetic analysis }\end{array}$ & & 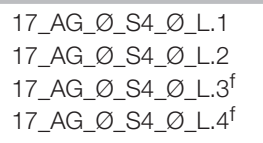 & & \\
\hline 17_AG_Ø_S5_Ø & Detection & & & & \\
\hline 17_AG_Ø_S6_Ø & Detection & & & & \\
\hline 17_AG_Ø_S7_ø & Detection & & & & \\
\hline 17_AG_Ø_S8_Ø & Detection & & & & \\
\hline 17_AG_Ø_S9_Ø & Detection & & & & \\
\hline 17_AG_Ø_S10_Ø & Detection & & & & \\
\hline 17_AG_Ø_S11_Ø & Detection & & & & \\
\hline
\end{tabular}

${ }^{a}$ The notation of each sample refers to: Year_location_plot_tissue_plant. The symbol Ø indicates absence of data.

${ }^{b}$ RNAs were extracted from individual plants and their quality and integrity checked independently; each pool was formed by four or five RNA extracts of RIN $\geq 8$ from samples from leaves or roots from a plant of the same plot.

${ }^{c-i}$ Identical numbers denote identical nucleotide sequences. Only one sequence from each group of identical sequences has been used for phylogenetic analysis.

because our preliminary tests showed interference from the compounds used in pelleting with nucleic acid extraction (data not shown). Total RNA for virus detection from lettuce leaves, roots and seeds was extracted using Nucleospin RNA plant Kit following the manufacturer's instructions (Macherey-Nagel, Germany). 


\section{sRNA Library Construction and Bioinformatic Analyses}

RNA integrity numbers (RIN) were determined for each RNA extract using a 2100 Bioanalyzer System (Agilent, USA); these figures were used to decide whether or not RNA samples could be used for sRNA-seq. Only RNA extracts of RIN $\geq 8$ were mixed in pools; thus pools 1-3 (Table 1) are composed of 45 RNA extracts from leaves or roots from 3 different plants from plots 1-3 (see above), respectively. The RNA pools were sent to Fasteris Life Sciences (Switzerland) for sRNA-seq. sRNAs 18-30 nt in length were size-selected from 2 to $3 \mu \mathrm{g}$ of total RNA from each pool by polyacrylamide gel electrophoresis and sRNA libraries were prepared using TruSeq Small RNA Library Prep Kit (Illumina). Equimolar amounts of each sRNA library were pooled for multiplexed sequencing in a single lane on an Illumina HiSeq 4000 instrument (50 bp, single-end). After adapter removal, the quality of the reads was assessed using FastQC $^{3}$. Reads were filtered by length (16-31 nts) and noncoding RNAs from the Rfam database were removed using Bowtie (Langmead et al., 2009). To search for virus sequences in the datasets, sequenced reads from each pool were submitted to the VirusDetect v1.7 online tool (Zheng et al., 2017). The lettuce genome (UC Davis Genome Center, CA, USA) was used as the reference to subtract host sRNAs. The percentage of identity of the VirusDetect viral contigs against different MiLBVV and LBVaV CP reference sequences was calculated by BLASTN using a command line standalone BLAST + program. Consensus sequences of $\mathrm{CP}$ genes of either MiLBVV and $\mathrm{LBVaV}$ were built using SAMtools mpileup and BCFtools (Sanger Institute) from BAM files determined by mapping the sRNA reads once again against the reference viral sequences using BWA aln algorithm (Li and Durbin, 2009). Raw sRNA-seq data have been deposited in the Sequence Read Archive of NCBI under identifier SRP169058.

To analyse virus-derived small RNAs (vsRNA) populations, sRNA reads were again mapped to each viral genome of the MiLBVV isolate LS301-S and the LBVaV isolate LS302 using Bowtie allowing no mismatches to retain only true vsRNAs. Counting of total and unique vsRNAs as well as size and orientation distributions and composition of the $5^{\prime}$ end nucleotide of vsRNAs were calculated using our own Perl Scripts ${ }^{4}$. Distribution plots of vsRNAs against viral genomes were displayed using MISIS (Seguin et al., 2014).

\section{Cloning and Sequencing of the CP ORFs}

RNA samples for cloning came from the pools 1, 2, and 3 used for sRNA-seq, and also from individual samples included in the pools, two samples from plot 4 (see above), as well as different seed samples (Table 1). RT and PCR amplification of the complete CP ORFs were performed in a two-step reaction. First-strand cDNA was synthesized using reverse primers MiLBVV_CP_R and LBVaV_CP_R (Table 2), respectively, and Expand Reverse Transcriptase (Roche Applied Science, Germany) or SuperScript ${ }^{\circledR}$ IV

\footnotetext{
${ }^{3}$ http://www.bioinformatics.babraham.ac.uk/projects/fastqc/

${ }^{4}$ https://github.com/ldonaire/Perl-scripts
}

Reverse Transcriptase (Invitrogen, USA) following the manufacturer's instructions. PCR was performed in a $50 \mu \mathrm{l}$ reaction using primer pairs MiLBVV_CP_F/MiLBVV_CP_R and LBVaV_CP_F/LBVaV_CP_R (Table 2), respectively, and the Expand High Fidelity PCR System (Roche Applied Science). PCR products were analyzed by agarose gel electrophoresis and DNAs of the expected sizes (Table 2) were recovered from gels using the GeneClean turbo kit (MP Biomedicals, Europe) according to manufacturer's recommendations. PCR products were ligated into pGEM $^{\circledR}$-T EasyVector (Promega Corp., USA), following manufacturer's instructions. Escherichia coli Stellar Competent Cells (Clontech, Takara Bio, Europe) were transformed following the supplier's protocol. Four recombinant clones were chosen for each PCR product. DNA plasmids were purified with GeneJET Plasmid Miniprep Kit (Thermo Fisher Scientific, USA) following the manufacturer's protocol. The presence and size of inserts was confirmed with a EcoR1 restriction digest of purified plasmid DNA. Sequencing of inserts in plasmids was done by Sanger sequencing (Stab Vida S.L., Portugal) using universal and internal primers (LBVaV_CP_F2, LBVaV_CP_R2, MiLBVV_CP_F2, MiLBVV_CP_R2) (Table 2).

Nucleotide sequences are deposited in the NCBI database under accession numbers MH894447 to MH894472 (MiLBVV) and MH894473 to MH894508 (LVBaV).

\section{Population Diversity and Phylogenetic Analyses}

The Molecular Evolutionary Genetics Analysis Version 7.0 (MEGA7) software (Kumar et al., 2016) was used to prepare multiple alignments of nucleotide sequences. Substitution models with the lowest BIC (Bayesian Information Criterion) scores were selected. Phylogenies were generated using the Maximum Likelihood method (Felsenstein, 1981), with 1000 bootstrap replicates. A Bayesian analysis was performed using the Beast v.1.8.4 program (Bouckaert et al., 2014). The substitution models chosen for that analysis were the same as those used for the maximum likelihood analysis. The resulting trees were constructed using treeAnnotator (available in the BEAST package) and edited using FigTree v1.4.3. The pairwise genetic distances between sequences were calculated using the MEGA7 software as well. Clustal X (2.1), a windows interface for Clustal $\mathrm{W}$, was used to determine the percent nucleotide identity matrix (Thompson et al., 1997). The degree of functional restriction for the preservation of the $\mathrm{LBVaV}$ and MiLBVV CP coding regions was estimated from the ratio of nucleotide diversities at nonsynonymous vs. synonymous positions (dN/dS); we used the NeiGojobori method (Nei and Gojobori, 1986) and the Kimura-2 parameters (Kimura, 1980) for MiLBVV and LBVaV, respectively, according to indications by the MEGA7 software.

\section{Virus Detection by Conventional and Quantitative RT-PCR}

Whenever possible, primers described in the literature were used for virus detection and quantification (Navarro et al., 2004; Momonoi et al., 2015). Otherwise, primers were designed in conserved regions of the $\mathrm{CP}$ encoding genes using the Primer3 
TABLE 2 | Primer and probe sequences.

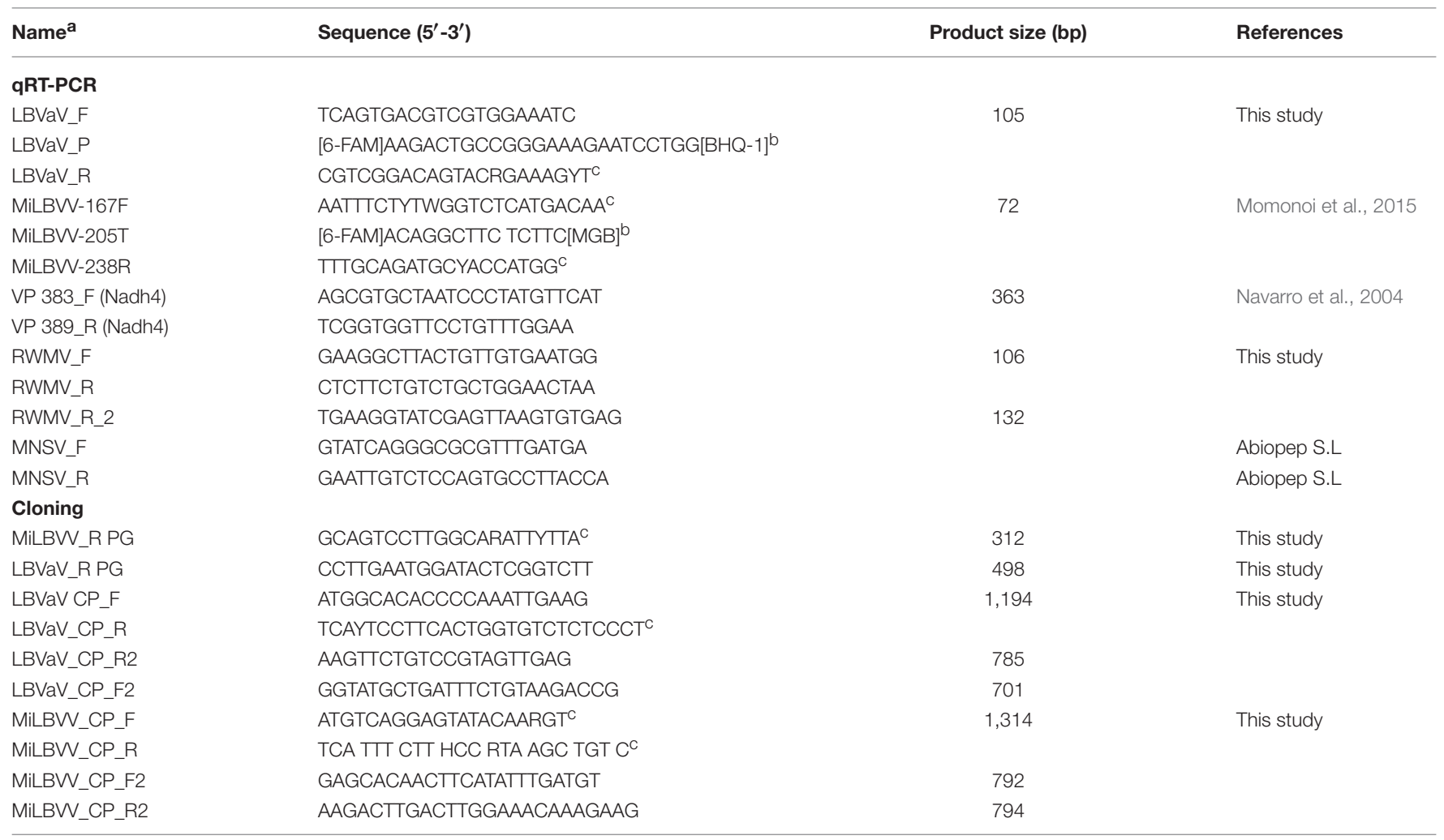

${ }^{a}$ F, forward primer; $R$, reverse primer.

${ }^{b}$ Dual-labeled fluorescent probe.

${ }^{c}$ Degeneracies: R: A or G; Y: C or T; W: A or T; H: A or C or T.

program (v.0.4.0) (Table 2). sRNA-seq results were validated by semi-quantitative RT-PCR. One hundred ng of the same RNA prep used for sRNA library construction were used for RTPCR. Primers for MiLBVV and LBVaV are described below. For RWMV we tried semi-quantitative RT-PCR using primer pairs RWMV_F/RWMV_R and RWMV_F/RWMV_R_2 (Table 2) but without success. For MNSV we used MNSV_F/MNSV_R (Table 2). To determine primer efficiency in MiLBVV and LBVaV qRT-PCRs, a standard curve was elaborated using a transcribed RNA synthesized in our laboratory for each virus. To clone the cDNA of the transcript, additional primers MiLBVV167F/MiLBVV_R PG and LBVaV_F/LBVaV_R PG (Table 2) were designed in the region of the CP genes to RT-PCR amplify fragments of $312 \mathrm{bp}$ for MiLBVV and $498 \mathrm{bp}$ for LBVaV. The obtained PCR products were electrophoresed in a $0.7 \%$ agarose gel, purified and cloned as described below. Once the inserts were cloned in pGEM-T Easy, the plasmids were linearized and transcribed with T7 RNA Polymerase (Promega), following the manufacturer's instructions. After transcription, treatment with DNase (Promega) and precipitation of RNA with sodium acetate were carried out to remove plasmid DNA. The transcribed RNAs were checked by agarose gel electrophoresis and quantified. The standard curve was made from 5 serial 1:10 dilutions of each of the synthesized transcripts. The qRT-PCR reactions were carried out in a StepOnePlus Real-Time PCR System (Applied Biosystems, USA) in a final volume of $10 \mu \mathrm{l}$ with KAPA SYBR FAST One-Step qRTPCR Master Mix (2X) Kit (Kapa Biosystems, USA) and the primers LBVaV_F/LBVaV_R and MiLBVV-167F/MiLBVV-238R (Table 2). The PCR conditions were: reverse transcription at $42^{\circ} \mathrm{C}$ for $5 \mathrm{~min}$, denaturation at $95^{\circ} \mathrm{C}$ for $3 \mathrm{~min}$, and 40 cycles of $3 \mathrm{~s}$ at $95^{\circ} \mathrm{C}$ followed by $20 \mathrm{~s}$ at $60^{\circ} \mathrm{C}$. Dissociation curves were used to evaluate the generation of non-specific products. Analysis of copy number, linear regression and melting curve analysis were performed with the StepOnePlus version 2.3 software. The housekeeping gene used as control was the mitochondrial $\mathrm{NADH}$ dehydrogenase subunit 4 (Nadh4) coding gene from lettuce; for this, primers used were VP383_F and VP389_R (Table 2). For MiLBVV and LBVaV detection in seeds, we used an additional method based on TaqMan probes (Table 2). Differences in virus accumulation among samples were analyzed by one-way or two-way ANOVA using Statgraphics Plus 5.1 software.

\section{RESULTS}

\section{Sequencing of sRNAs From Symptomatic Lettuce Plants}

We surveyed lettuce crops in open fields in Murcia (Southeast Spain), which is one of the major lettuce exporter regions in the world ${ }^{1}$. Surveys took place during 2016, 2017, and 2018, 
and our visual inspection suggested an incidence of LVBD-like symptoms close to $45 \%$ (Figure 1), with no obvious differences among lettuce cultivars. Three RNA pools from diseased plants from three different field plots (Table 1) were used for sRNAseq, which produced 101-142 million reads (Table 3). The more abundant reads ranged in size from 18 to $26 \mathrm{nt}$, which fitted well with the canonical sRNA size classes. Reads of 16 to 31 nt were mapped against the Rfam database to discard noncoding RNA sequences. Thus, a total of $101,807,022 ; 79,763,445$; and $71,875,996$ reads in pools $1-3$, respectively, were submitted to the VirusDetect online tool (Zheng et al., 2017) for virus identification using its plant virus database. From the total reads, $44-73 \%$ mapped to the lettuce genome, whereas $0.3-$ $6 \%$ mapped to plant virus genomes (Table 3). Virus sRNA (vsRNA) reads could be assembled into 730, 226, and 2075 unique contigs in pools $1-3$, respectively (Table 3 ). According to a VirusDetect BLASTN search, 101, 69 and 171 of those contigs could be mapped against 7, 10 and 8 different MiLBVV or LBVaV sequence accessions in each sample pool, respectively, with reference coverage ranging from 64.9 to $99.8 \%$ and average sRNA sequencing depth (normalized to reads per million) ranging from 0.4 to 66.9 (Supplementary Table 1 and Figure 2). In pools 1 and 2, contigs mapping to a second MiLBVVRNA3 sequence were found but with a genome coverage below 21.3\% (Supplementary Table 1 and Figure 2). VirusDetect also identified 24 contigs mapping to the RNA1 (AF335429), RNA2 (AY542957), and an unknown segment (AF335430) of ranunculus white mottle virus (RWMV; species Ranunculus white mottle virus, genus Ophiovirus, family Aspiviridae) genome in pool 2, with a reference coverage of $79.7-97.7 \%$ and a normalized sequencing depth of 1-15.2 (Supplementary Table 1 and Figure 2). Also, in pool 3,17 contigs mapped to melon necrotic spot virus (MNSV; species Melon necrotic spot virus, genus Alphacarmovirus, family Tombusviridae) genome, with a coverage of $26.1 \%$ and a normalized sequencing depth of 0.2 (Supplementary Table 1 and Figure 2). Semi-quantitative RTPCR was used to validate the presence of the above viruses in RNA pools; MiLBVV; and LBVaV were readily detected in all three pools, while neither RWMV nor MNSV could be confirmed in spite of the use of two primer pairs for the former.

Since the plant-virus database used by VirusDetect was processed to remove redundant sequences, a new BLASTN search was conducted to identify sequences closer to the viral sequences identified in our samples. For this, the viral contigs retrieved by VirusDetect were mapped against the $\mathrm{CP}$ sequences of different isolates of MiLBVV (22 sequences) and LBVaV (30 sequences) collected from NCBI, and their percentages of identity were recorded (Supplementary Table 2). Coverage was $100 \%$ in all cases. The highest percentage of identity was found for contigs mapping the CP sequence of isolate MiLBVVLS301-O for all pools (97-99.6\%) (Supplementary Table 2). In pool 3, other assembled contigs shared the highest sequence identity $(\sim 98.3 \%)$ to four isolates from the South of Spain (Supplementary Table 2; Navarro et al., 2005), suggesting the presence of isolates of different genetic groups in this pool.

\section{Characterization of Viral Small RNA Populations}

To our knowledge, this was the first time that vsRNAs were sequenced for MiLVBV and $\mathrm{LBVaV}$, so that a bioinformatics pipeline was used to characterize the vsRNA populations in our sRNA-seq datasets. vsRNAs from 20 to 24 nt that perfectly matched the reference viral genomes (isolate LS301$\mathrm{O}$ of MiLBVV and isolate LS302 of LBVaV) encompassed more than $90 \%$ of the total vsRNAs for pools 1 and 2, whereas for pool 3 this percentage ranged from 65.5 to $81.2 \%$. The total number of vsRNAs of 20-24 nt was variable among samples and among viral genomes, ranging from 1,654 for MiLBVVRNA4 in pool 3 to 1,567,448 for MiLBVV-RNA3 in pool 2. Likewise, the number of unique vsRNA sequences varied from 182 for MiLBVV-RNA4 in pool 3 to 12,610 for MiLBVV-RNA1 in pool 2. The size distribution of these vsRNAs was very similar between the three samples analyzed. vsRNAs were mostly 21 nt long (ranging from 29.4 to 52.2\%) followed by $22 \mathrm{nt}$ long (ranging from 19.7 to 34.4\%) (Figure 3A). vsRNAs derived from RNA1, RNA2, and RNA3 of MiLBVV were mostly of antisense polarity (ranging from $54.6 \%$ in RNA2 for pool 2 to $73.1 \%$ in RNA3 for pool 2) (Figure 3B). However, vsRNAs derived from RNA4 of MiLBVV were mostly of sense polarity (ranging from $88.4 \%$ in pool 3 to $63 \%$ in pool 1) (Figure 3B). LBVaV-RNA1derived vsRNAs were equally of sense and antisense polarity, but LBVaV-RNA2-derived vsRNAs of sense polarity were slightly more abundant (Figure 3B). In agreement with our previous analysis using VirusDetect, vsRNAs were distributed along the complete sequence of the viral genomes ( $90 \%$ of genome coverage in average), although their distribution was heterogeneous and there were vsRNA accumulation peaks located in specific regions of the viral genomes. As an example, we plotted both sense and antisense vsRNAs mapping to the RNA segment encoding the CP gene (RNA3 of MiLBVV and RNA2 of LBVaV) for all three sample pools (Figure 3C). The distribution of accumulation peaks in plots was very similar between samples, although the amount of vsRNAs for both viral genomes was lower for pool 3 than for pool 1 and much lower than for pool 2 (Figure 3C). Lastly, we analyzed the composition of the $5^{\prime}$ end of the vsRNAs, as the loading of sRNAs in the effector complexes is dictated by the identity of this nucleotide (Kim, 2008). Our analysis revealed that most vsRNAs had a $5^{\prime}$ end uridine for all viral genomes and in all three pools analyzed with the only exception of vsRNAs from RNA4 of MiLBVV in pool 3, which mostly had a cytosine in that position (Figure 3D). In general, vsRNAs derived from MiLBVV and LBVaV infecting lettuce shared common characteristics to previously described plant vsRNA populations and also vsRNAs from viruses infecting fungi or animals (Donaire et al., 2009; Parameswaran et al., 2010; Donaire and Ayllón, 2017; Li et al., 2017; Xu and Zhou, 2017; Kaldis et al., 2018; Lan et al., 2018).

\section{Diversity and Phylogenetic Analysis of the MiLBVV Population}

The region between nucleotides 12 and 1,325 of MiLBVV RNA3, which encodes the $\mathrm{CP}$, was selected for cloning and subsequent 

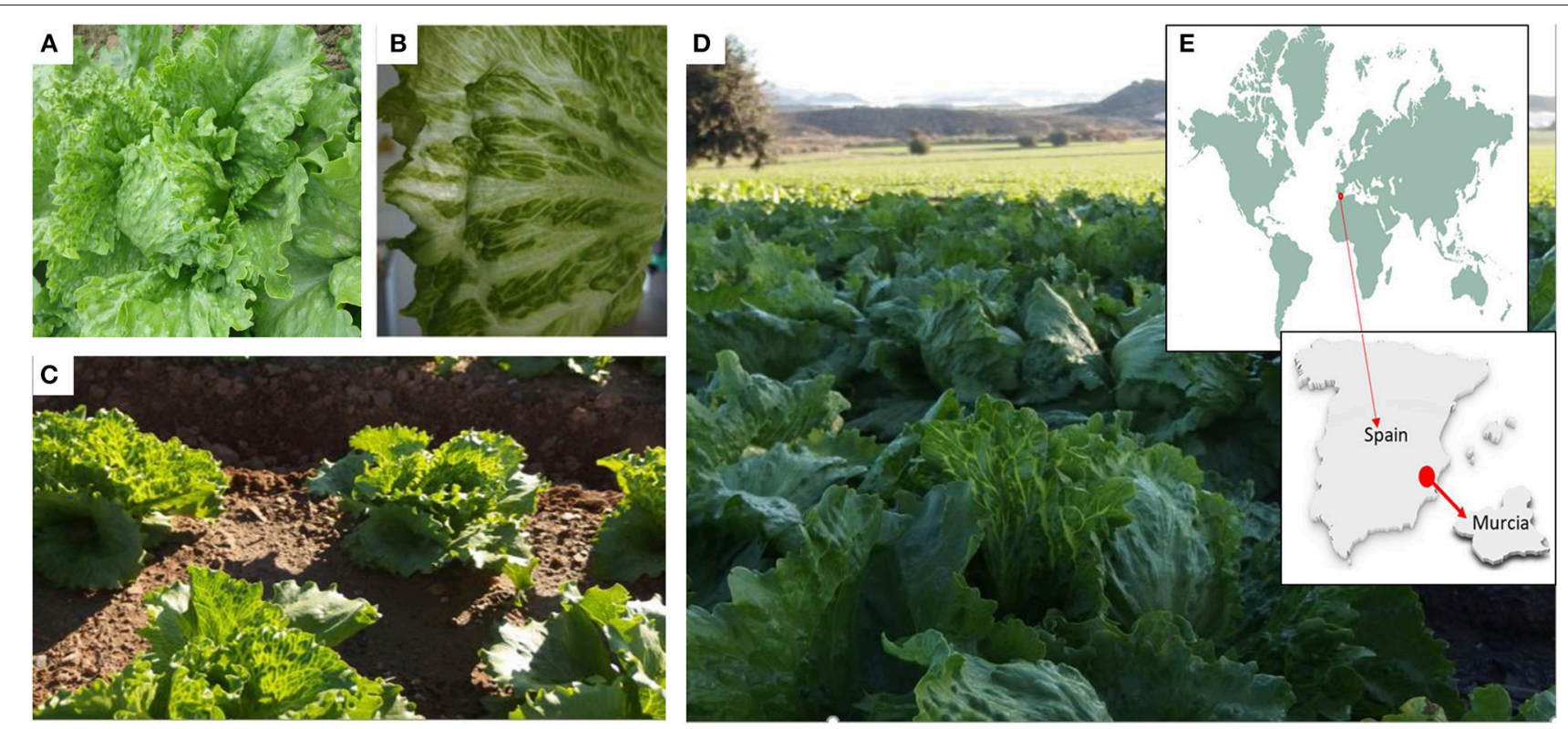

FIGURE 1 | Symptomatic lettuce plants and crops, and location of the area surveyed. (A,B) Details of lettuce leaves with LBVD symptoms. Affected lettuce crops at the beginning (C) or at the end (D) of the cropping season. Surveys took place in Murcia (E) which is the main lettuce producing region in Spain.

TABLE 3 | Summary of VirusDetect results of the three sample pools.

\begin{tabular}{|c|c|c|c|c|c|c|c|c|c|}
\hline Samples & $\begin{array}{l}\text { Adapter } \\
\text { removing }\end{array}$ & $\begin{array}{l}\text { Filtering by length } \\
\text { (16-31 nts) }\end{array}$ & $\begin{array}{l}\text { Rfam } \\
\text { mappings }\end{array}$ & $\begin{array}{l}\text { Submited to } \\
\text { VirusDetect }\end{array}$ & $\begin{array}{l}\text { Lettuce } \\
\text { mappings }\end{array}$ & $\begin{array}{l}\text { Virus } \\
\text { mappings }\end{array}$ & $\begin{array}{l}\text { Unique } \\
\text { contigs }\end{array}$ & $\begin{array}{l}\text { Unique contigs } \\
\text { mapping to } \\
\text { viruses }\end{array}$ & $\begin{array}{l}\text { Viruses } \\
\text { identified by } \\
\text { BLASTN }\end{array}$ \\
\hline Pool 2 & $101,966,562$ & $\begin{array}{c}96,932,063 \\
(95.06 \%)\end{array}$ & $\begin{array}{c}17,168,618 \\
(17.71 \%)\end{array}$ & $79,763,445$ & $\begin{array}{l}58,038,873 \\
(72.76 \%)\end{array}$ & $\begin{array}{c}4,582,701 \\
(5.75 \%)\end{array}$ & 226 & 69 & 10 \\
\hline
\end{tabular}

sequencing. We chose to use this strategy instead of direct sequencing of RT-PCR products to avoid uncertainties due to potential mixed infections. A total of $27 \mathrm{cDNA}$ clones were prepared from either individual or pooled samples, and up to 4 cDNA clones were sequenced per RNA extract (Table 1). Sequences were aligned and percentages of nucleotide identity were calculated between pairs of sequences using the Clustal Omega program (Sievers and Higgins, 2014), which ranged between 88.1 and $100 \%$. These percentages ranged from 86.9 to $100 \%$ for MiLBVV CP sequences included in the NCBI database (Supplementary Table 3). Non-redundant sequences were aligned and used for phylogenetic analyses (Figure 4), in which we included the blueberry mosaic associated virus (BIMaV, species Blueberry mosaic associated virus, genus Ophiovirus) $\mathrm{CP}$ sequence (NC 036634.1) as an outgroup. A first analysis in which only the sequences determined in this study were considered showed the existence of three branches in the phylogenetic tree (Figure 4A). The sequences within each branch were highly similar (99.3-99.9\% nucleotide identity), while pairs of sequences from different branches were more dissimilar
(87.7-97.8\% nucleotide identity). This phylogenetic analysis was complemented with a population analysis based on genetic distances, which allow for the estimation of the degree of genetic variation within and between populations (Nei et al., 2001). Distances among pairs of sequences were estimated using the Tamura-Nei method (Tamura, 1992; Tamura and Nei, 1993). Results showed that the mean nucleotide distance among the whole set of sequences was $0.052 \pm 0.004$, whereas for sequences within branches these values ranged from $0.004 \pm 0.001$ to $0.001 \pm 0.000$, suggesting genetic differentiation. Therefore, our analyses suggested the existence of at least three viral strains in the geographic area under study.

MiLBVV nucleotide sequences from the NCBI database (Supplementary Table 3) were included in a second phylogenetic analysis. The basic branching pattern for this tree was similar to the previous one, again identifying three main lineages (Figure 4B). The percentages of nucleotide identity among pairs of sequences within the three main branches ranged between 96.1 and $99.9 \%$ for branch I, 97.9 to $99.9 \%$ for branch II, and 97.6 and $99.9 \%$ for branch III, supporting the existence of these 


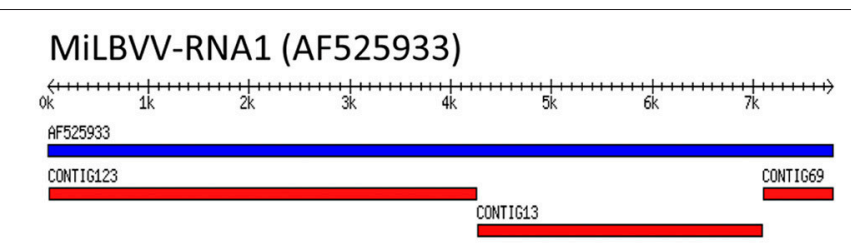

MiLBVV-RNA2 (AF525934)

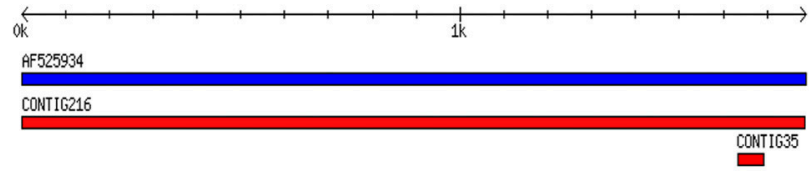

MiLBVV-RNA3 (AF525935)

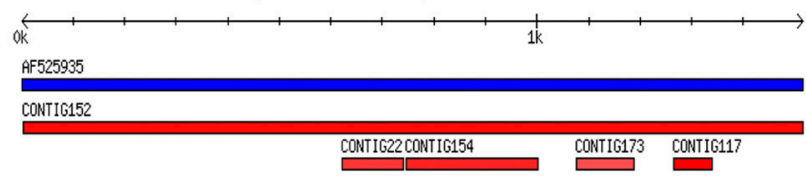

MiLBVV-RNA3 (AY581701)

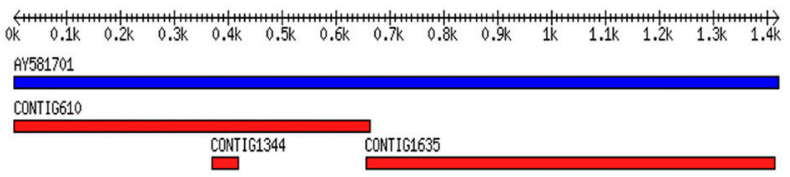

\section{MiLBVV-RNA4 (AF525936)}

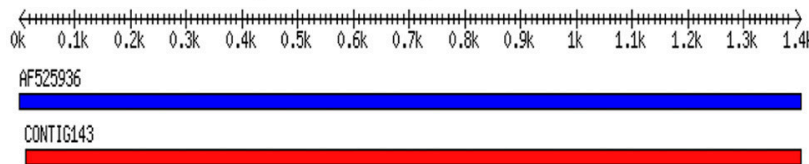

LBVaV-RNA1 (AB075039)

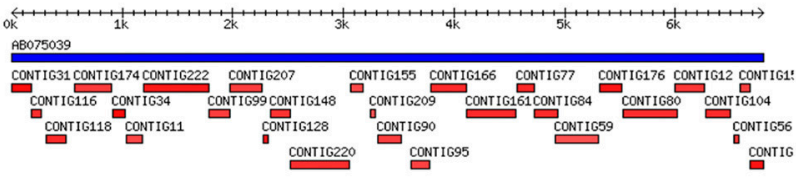

LBVaV-RNA2 (JN710441)

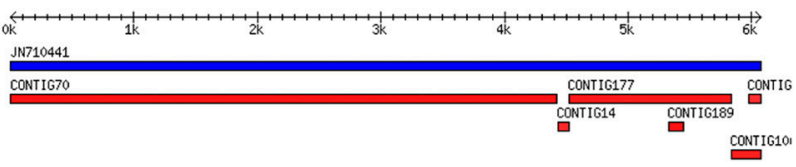

RWMV-RNA1 (AY542957)

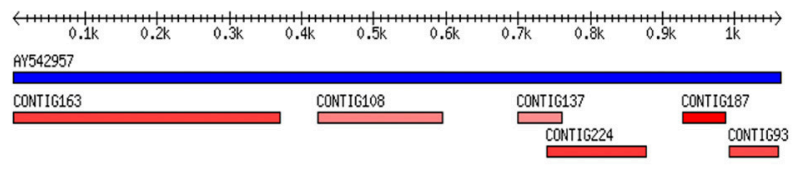

RWMV-RNA2 (AF335429)

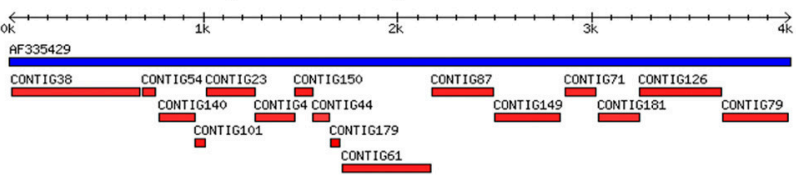

MNSV (AY122286)

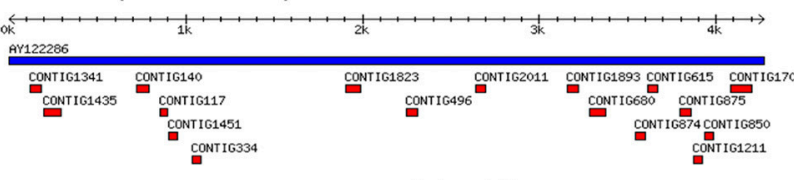

Identity $100 \% \square$

FIGURE 2 | Schematic representation of virus contigs identified by VirusDetect. Distribution of contigs assembled by VirusDetect (in red) along the corresponding reference viral genomes (in blue). The accession numbers of the reference viral sequences are shown in brackets. The percentage of identity of the contigs with the reference sequences is shown as a color-scale. Tracks are those with better coverage, which corresponded to pool 2 except those matching accessions AY581701 and AY122286 that derived from pool 3.

three well differentiated lineages. While branch III grouped only Spanish sequences, for branches I and II there was no apparent relationship between geography (place where the isolate was from) and position in the tree. Thus, the Spanish sequences of branch I appeared related to other earlier Spanish sequences from Almería, Murcia and Galicia, but also to one sequence from Italy, one from Germany and two from Argentina, and the Spanish sequences in branch II appeared related to one from Germany (Figure 4B). Phylogenetic reconstruction using Bayesian methods suggested that diversification of groups I and II occurred $~ 76.2$ years ago (Node a; HPD 95\% 24.6-384 years), and that the lineage including the most prevalent type of sequences in this study diverged from a German sequence $\sim 28.2$ years ago (Node b; HPD 95\% 14.8-53.8 years) (Figure 4C).

An analysis of the direction and intensity of the selection acting on the CP was also carried out (Table 4). The number of synonymous $(\mathrm{dS})$ and non-synonymous $(\mathrm{dN})$ substitutions between pairs of sequences was estimated to determine the coefficient $\mathrm{dN} / \mathrm{dS}$, which when $>1$ suggests that the gene is under positive selection, when $<1$ suggests that the gene is under negative or purifying selection, and when equal to 1 , the gene is under neutral selection. In general, the $\mathrm{dN} / \mathrm{dS}$ ratios estimated for the nucleotide sequences were smaller than 1 (Table 4), suggesting that the MiLBVV CP gene was under negative, purifying selection.

\section{Diversity and Phylogenetic Analysis of the LBVaV Population}

As for MiLBVV, cDNAs for the LBVaV CP gene were cloned and sequenced, generating 29 good quality sequences from cDNA clones derived from either individual or pooled samples. $\mathrm{Up}$ to 4 cDNA clones were sequenced per RNA extract (Table 1). Sequences were aligned and nucleotide identities were calculated; nucleotide identities varied from 98.8 to $100 \%$, already showing lesser diversification of the $\mathrm{LBVaV}$ population compared to the MiLBVV population. When LBVaV CP 

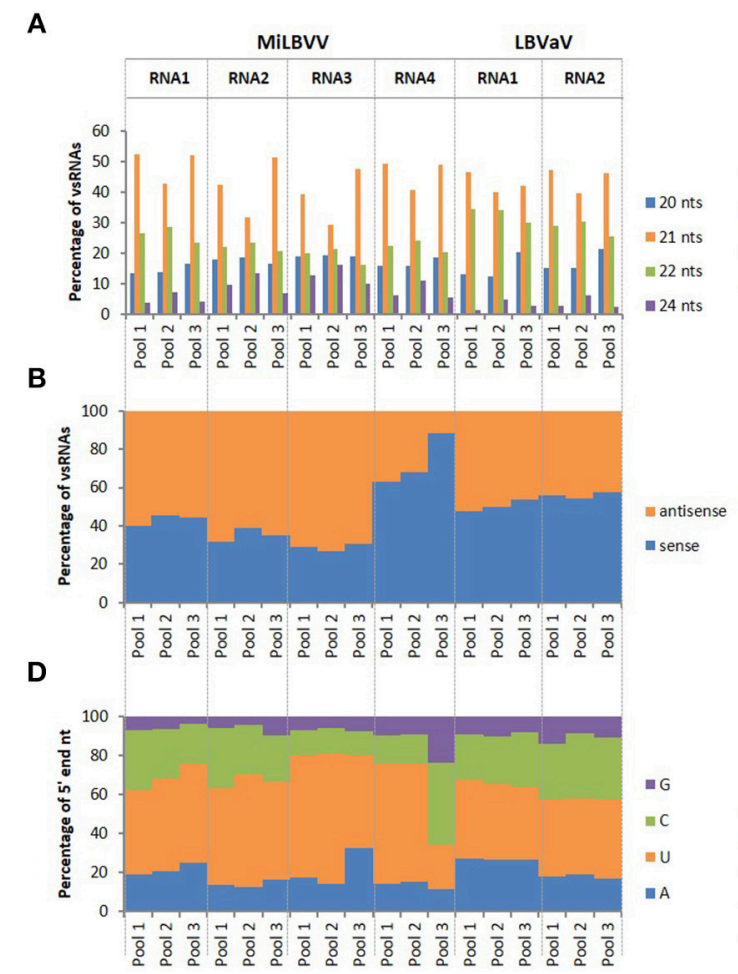
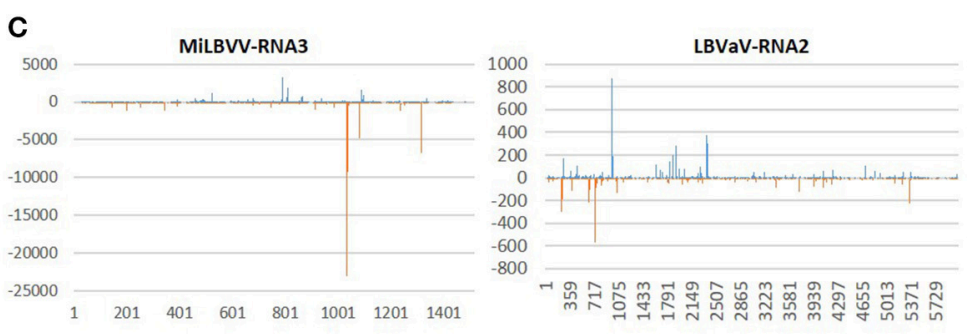

Pool 1
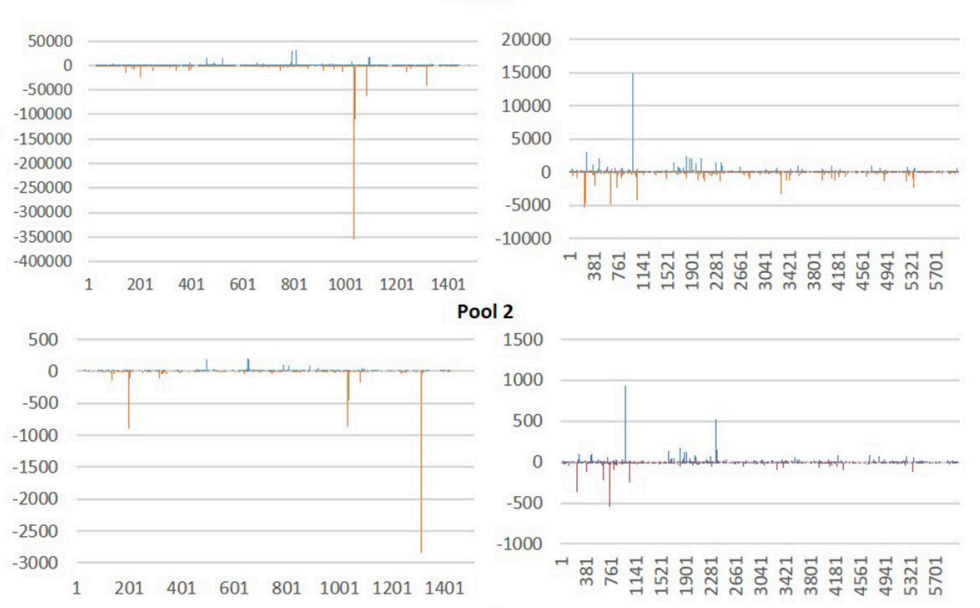

FIGURE 3 | Features of vsRNAs derived from LBVD-associated viruses. (A) Size distribution of the more abundant total vsRNAs. (B) Orientation distribution of total vsRNAs. (C) Distribution of vsRNAs along MiLBW RNA3 and LBVaV RNA2. (D) 5' end nucleotide composition of vsRNAs.

sequences from the NCBI database (Supplementary Table 2) were included in the analysis, percentages of nucleotide identity varied from 93.9 to $100 \%$. Phylogenetic analyses (Figure 5) were carried out including the 23 non-redundant sequences determined here. The sequence of the tobacco stunt virus (TStV; species Tobacco stunt virus, genus Varicosavirus) CP gene (ref AB190525.1) was used as the outgroup. In this case, due to the low variability in the population, an analysis with only the sequences determined in this study resulted in trees with low confidence branching patterns, independently of the phylogenetic reconstruction method used (data not shown). In contrast, when nucleotide sequences from the NCBI database (Supplementary Table 2) were included, phylogenies were fully informative. Two main nodes with bootstrap values above $95 \%$ could be identified; the branches radiating from these nodes grouped sequences from common geographical origins: Branch I grouped European and Australian sequences and branch II grouped Japanese sequences (Figure 5A). Branch I could be differentiated into linages Ia that grouped European sequences and lineage $\mathrm{Ib}$, which included Australian sequences. The percentages of nucleotide identity for sequences within branches I, Ia, Ib and II ranged between 95.5-99.9\%, 95.5-99.9\%, 98.3$99.7 \%$, and $99.1-99.75 \%$, respectively, whereas for sequences between branches, the percentages ranged between $95.5-98.4 \%$, 93.9-96.9\%, and $95.73-96.9 \%$ for the pairs Ia-Ib, Ia-II, and Ib-II, respectively.
A population analysis based on genetic distances (Nei et al., 2001), in this case estimated using the Kimura 2-parameter method (Kimura, 1980), showed that the mean nucleotide distance among the LVBaV sequences determined in this work was $0.005 \pm 0.001$, again illustrating the lesser diversity found in the LVBaV population compared to MiLBVV. For the whole set of sequences used in the phylogenetic analysis, this datum was $0.018 \pm 0.002$. Within branches Ia, Ib and II, the mean nucleotide distances were $0.010 \pm 0.001,0.011 \pm 0.002$, and $0.007 \pm 0.002$, respectively, whereas these values for sequences between branches were $0.025 \pm 0.005,0.046 \pm 0.006$, and $0.040 \pm 0.004$ for the pairs Ia-Ib, Ia-II, and Ib-II, respectively. These data, together with our phylogenetic analyses, support the existence of $\mathrm{LVBaV}$ populations differentiated according to geography. Bayesian analysis suggested that the European and Australian sequences diverged 91.55 years ago (Node a; HPD 95\% 48.4-157.3 years), and the Spanish sequences diverged from sequences from the United Kingdom and The Netherlands 62.8 years ago (Node b; HPD 95\% 35.4-103 years) (Figure 5B); interestingly, the latter sequences shared ancestors with again Spanish sequences, suggesting the exchange of LBVaV isolates within the European territory. As before, $\mathrm{dS}$ and $\mathrm{dN}$ substitutions between pairs of sequences were estimated to determine the $\mathrm{dN} / \mathrm{dS}$ ratios (Table 4). Independently of the subpopulation considered, these ratios were always below 1 , which suggests that the LBVaV CP gene was also under negative selection. 


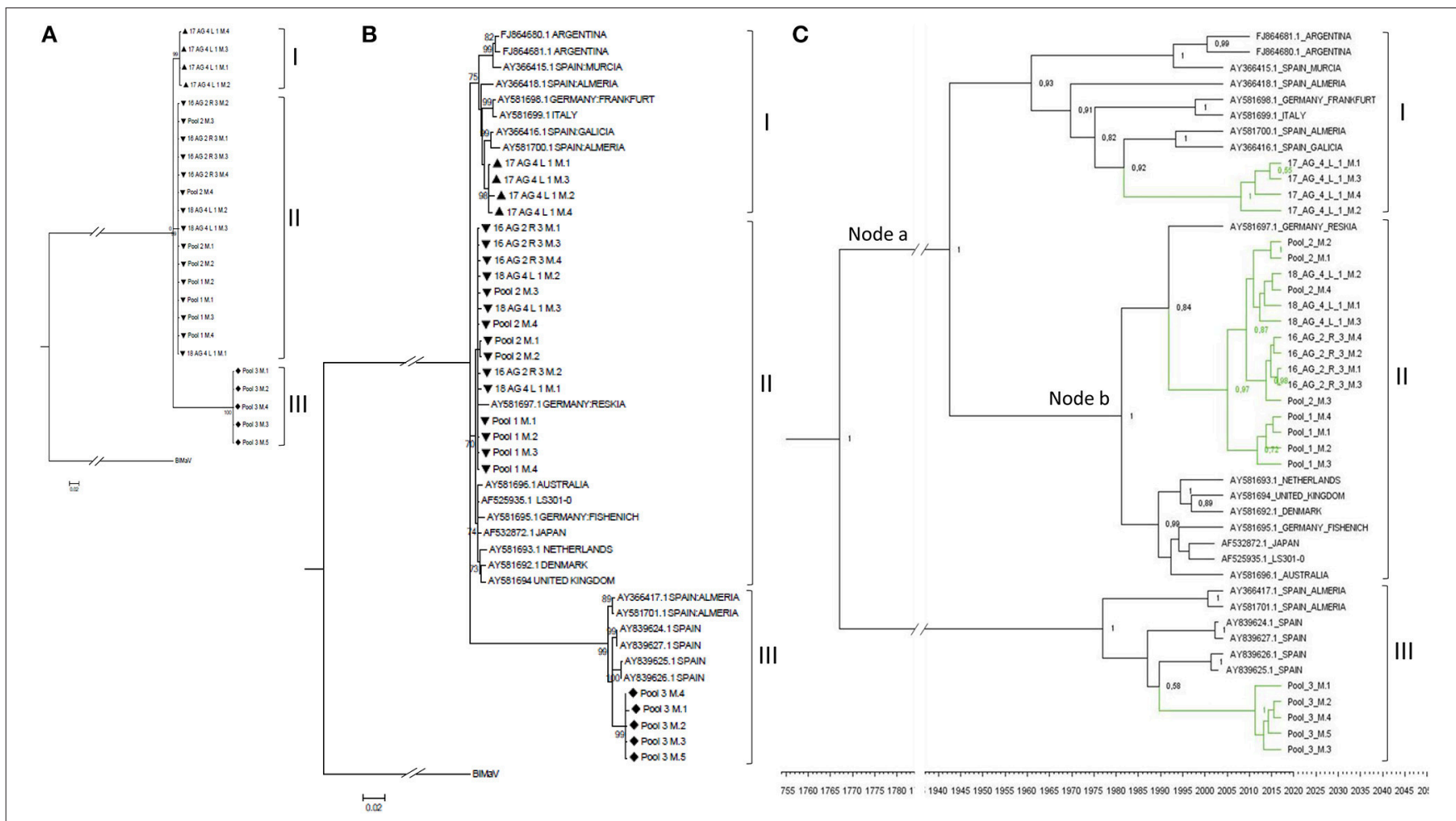

FIGURE 4 | Phylogenetic relationships among the complete CP nucleotide sequences of MiLBV isolates. The evolutionary history was inferred using the Maximum Likelihood method with 1000 bootstrap replicates, applying the Tamura-Nei+G model. Branch nodes with $<70 \%$ bootstrap values were collapsed. Symbols before the sequence names correspond to: Triangles, sequences determined in this work belonging to group I; Upside-down triangles, sequences determined in this work belonging to group II; Diamonds, sequences determined in this work belonging to group III. (A) Tree constructed with 24 non-redundant sequences determined in this work and rooted with blueberry mosaic associated virus CP sequence (ref. NC 036634.1). (B) Tree constructed including additional MiLBW sequences from other databases. (C) Bayesian Maximum Clade credibility tree. Node labels correspond to posterior probability support values (values below $50 \%$ are not shown). The inferred divergence time is shown below the tree. Sequences were named according to the GenBank accession number except for the sequences identified in this study (colored in green), which were named with their sequence codes (Table 1).

\section{MiLBVV and LBVaV Detection in Additional Field Samples, Including Seeds}

An alignment of LBVaV CP consensus sequences from the sRNAseq analysis above and LBVaV sequences available in the NCBI database allowed for the design of conserved primers for this virus. We also checked sequence conservation for the MiLBVV primers designed by Momonoi et al. (2015) using the sequences determined in this study. The complete set of primers (Table 2) can amplify fragments in the $\mathrm{CP}$ genes of both viruses. Using these primers, we analyzed the presence of the two viruses in new lettuce samples to (i) detect the presence of both viruses in samples from commercial crops and seed lots and (ii) identify the best tissues to sample for virus detection. We thus sampled leaves and roots of 26 lettuce plants from fields from Águilas (Murcia, Spain) which were very affected by LBVD; out of these, 14 plants were asymptomatic. All leaf samples were positive for $\mathrm{LBVaV}$, as were roots, but differences were observed for MiLBVV; all symptomatic and $85.7 \%$ of the asymptomatic leaf samples were infected by MiLBVV, whereas 58.3 and $92.9 \%$ of the root samples from symptomatic and asymptomatic plants, respectively, were infected by MiLBVV. We then hypothesized that qualitative MiLBVV detection discrepancies in roots and leaves could be due to differences in virus accumulation in the different tissues. Therefore, we next studied the accumulation of both viruses in leaves vs. roots, young leaves vs. old leaves, and symptomatic vs. asymptomatic leaves (Figure 6). Our data showed that LBVaV accumulated to higher levels than MiLBVV, and differences for the different classes of tissues (leaves, roots, symptomatic, asymptomatic) were only statistically significant for old vs. young MiLBVV-infected leaves (Figure 6). This is notorious in the case of asymptomatic plants, which accumulated equivalent amounts of viral RNA than symptomatic plants. We also analyzed seeds from 11 different varieties from 5 different commercial providers (Table 5). For each virus we used two PCR-based methods, particularly a confirmatory method using TaqMan probes (Table 2) to improve specificity. Both methods provided similar results, seeds from varieties 1 and 2 were positive for both viruses, seeds from varieties 3, 4, 5, 6, and 9 were positive by LBVaV only, and seeds from varieties $7,8,10$, and 11 were negative (Table 5). To confirm these results and for further analysis, the regions encoding viral CPs were cloned and sequenced. Two cDNA clones were obtained for MiLBVV and 15 for LBVaV from positive seeds samples (Table 1). Phylogenetic analyses including these sequences showed that MiLBVV seed 
TABLE 4 | Average number of nucleotide substitutions ${ }^{a}$ among MiLBW and LBVaV CP coding regions.

\begin{tabular}{lccc}
\hline Virus & $\mathbf{d N}^{\mathbf{b}}$ & $\mathbf{d S}^{\mathbf{c}}$ & $\mathbf{d N / d S}$ \\
\hline MiLBWV & $0.013 \pm 0.002$ & $0.224 \pm 0.021$ & 0.058 \\
MiLBWV Clade I & $0.009 \pm 0.002$ & $0.053 \pm 0.007$ & 0.169 \\
MiLBW Clade II & $0.004 \pm 0.001$ & $0.019 \pm 0.004$ & 0.211 \\
MiLBW Clade III & $0.002 \pm 0.001$ & $0.036 \pm 0.007$ & 0.056 \\
MiLBW from Águilas & $0.011 \pm 0.002$ & $0.218 \pm 0.022$ & 0.050 \\
LBVaV & $0.005 \pm 0.001$ & $0.043 \pm 0.006$ & 0.116 \\
LBVaV Clade I & $0.005 \pm 0.001$ & $0.031 \pm 0.005$ & 0.161 \\
LBVaV Sub-Clade la & $0.005 \pm 0.001$ & $0.026 \pm 0.004$ & 0.192 \\
LBVaV Sub-Clade Ib & $0.005 \pm 0.002$ & $0.023 \pm 0.006$ & 0.217 \\
LBVaV Clade II & $0.001 \pm 0.001$ & $0.021 \pm 0.006$ & 0.048 \\
LBVaV from Águilas & $0.002 \pm 0.000$ & $0.014 \pm 0.004$ & 0.143
\end{tabular}

${ }^{a}$ Estimated using the Nei and Gojobori (Nei and Gojobori, 1986) or Kimura 2-parameter (Kimura, 1980) methods for MiLBWV or LBVaV, repectively. Sequences are those included in phylogenetic analysis in Figures $\mathbf{4 B}, \mathbf{5 A}$; values have been estimated also for the Spanish sequences determined in this work ("from Águilas").

${ }^{b}$ Mean nucleotide diversity in non-synonymous positions.

${ }^{c}$ Mean nucleotide diversity in synonymous positions.

sequences grouped with lineage II sequences, which included most of the sequences determined in this work for MiLBVV (Supplementary Figure 1). The $15 \mathrm{LBVaV}$ seed sequences were grouped in lineage Ia, which included the European and Spanish sequences analyzed in this work (Supplementary Figure 2).

\section{DISCUSSION}

Our results have confirmed (see for example Zaagueri et al., 2017) that VirusDetect coupled to sRNA-seq is an efficient tool for identifying viruses infecting plants from commercial crops. In agreement with previous work, the viruses detected in association with LBVD were MiLBVV and LBVaV, although we also identified sequence reads corresponding to RWMV and MNSV in pools 2 and 3, respectively. The relevance of RWMV remains to be determined, as we were unable to confirm its presence using qRT-PCR (data not shown) in spite of genome coverage in pool 2 equivalent or slightly smaller than that for MiLBVV or LBVaV and the use of two different primer pairs in RT-PCR. In this regard, a recent study comparing the sensitivity of sRNA-seq vs. RT-PCR for virus identification using total RNA from different species showed that their detection limits were very similar; however, sRNA-seq was 10 times more sensitive than RT-PCR for detection of already-known viral genomes (Santala et al., 2018). In the case of MNSV, its detection was surely negligible and probably associated to the sampling of lettuce roots, perhaps contaminated with sporangia of viruliferous Olpidium bornovanus, the MNSV vector, from cucurbit crops that rotated in the area before lettuce. VirusDetect also has the potential for finding mixed strain infections; we identified different contigs in one of our sample pools with variable similarity to the reference MiLBVV genome, showing that the identification of contigs belonging to different virus strains is feasible using this suite of programs. However, the
VirusDetect potential for identification of the closest isolate present in a sequenced sample among all sequences in databases is limited. The use of a broader plant virus database containing all possible sequences could overcome this limitation, although it may not be feasible in practical terms due to excessive computing resources needs. Here, by using a local BLASTN alignment of the viral contigs against different $\mathrm{CP}$ sequences of MiLBVV and LBVaV, we found that the viral contigs in our samples were closely related to MiLBVV isolates from the Netherlands and Spain and LBVaV isolates from Spain. The subsequent Sanger sequencing of the CP sequences of the sRNA-seq sample pools and the phylogenetic analyses confirmed these results.

Using the sRNA-seq data, we have described for the first time the vsRNA populations from MiLBVV and LBVaV. vsRNAs play an essential role on the antiviral RNA silencing defense mechanisms in plants and may also participate in the regulation of host gene expression during viral infection (Llave, 2010). We showed that the characteristics of these vsRNA populations were essentially similar to those described for other plant viruses in terms of size, orientation and $5^{\prime}$ end nucleotide composition. These results suggest that the different sRNA biogenesis pathways are fully operative in lettuce and are probably the same than in other plant species, as suggested by the fact that most endogenous sRNAs corresponded to 24-nt heterochromatic small interfering RNAs and because conserved microRNAs were previously identified in lettuce (Reyes-Chin-Wo et al., 2017). The vsRNA profiles from our three different sample pools were almost identical, although some differences were found. For instance, the number of vsRNAs derived from all viral genomes in pool 2 was much higher than in pools 1 and 3, which could be correlated with higher viral replication or accumulation in samples in this pool, as was confirmed by qRT-PCR amplification (Supplementary Figure 3). Moreover, the higher percentage of coverage found for all viral genomes in pool 2, as compared with the other sample pools (Supplementary Table 1) could be a reflection of high viral accumulation, as it has been described that high viral amounts result in an almost complete coverage of vsRNAs along the reference genomes (Santala et al., 2018). vsRNAs derived from MiLBVV and LBVaV in the three sample pools were mostly 21 and $22 \mathrm{nts}$ in length, which suggests that the same dicer-like ribonucleases, likely to be DCL4 and DCL2, are involved in their biosynthesis, as for vsRNAs derived from any viral genome characterized to date (Donaire et al., 2008). With the exception of the MiLBVV RNA4, MiLBVV-derived vsRNAs of antisense polarity were predominant in the data sets. In the case of LBVaV, vsRNAs of sense and antisense polarity accumulated in a similar proportion or with a small bias toward vsRNAs of sense polarity in RNA2. For both viruses, the negative strands carry the genetic information, thus, it is possible that the accumulation of the negative-strands and/or their half-lives during viral infection cycles are higher than those of the positive strands, explaining results for MiLBVV RNAs 1, 2, and 3. Similar amounts of vsRNAs of both polarities could be explained if vsRNAs proceeded from viral dsRNAs formed during the replication cycle or by the activity of plant RNA dependent RNA polymerases (RDRs), as described for a negative-stranded RNA mycovirus (Donaire and Ayllón, 2017). The remarkable amount of vsRNAs of sense 


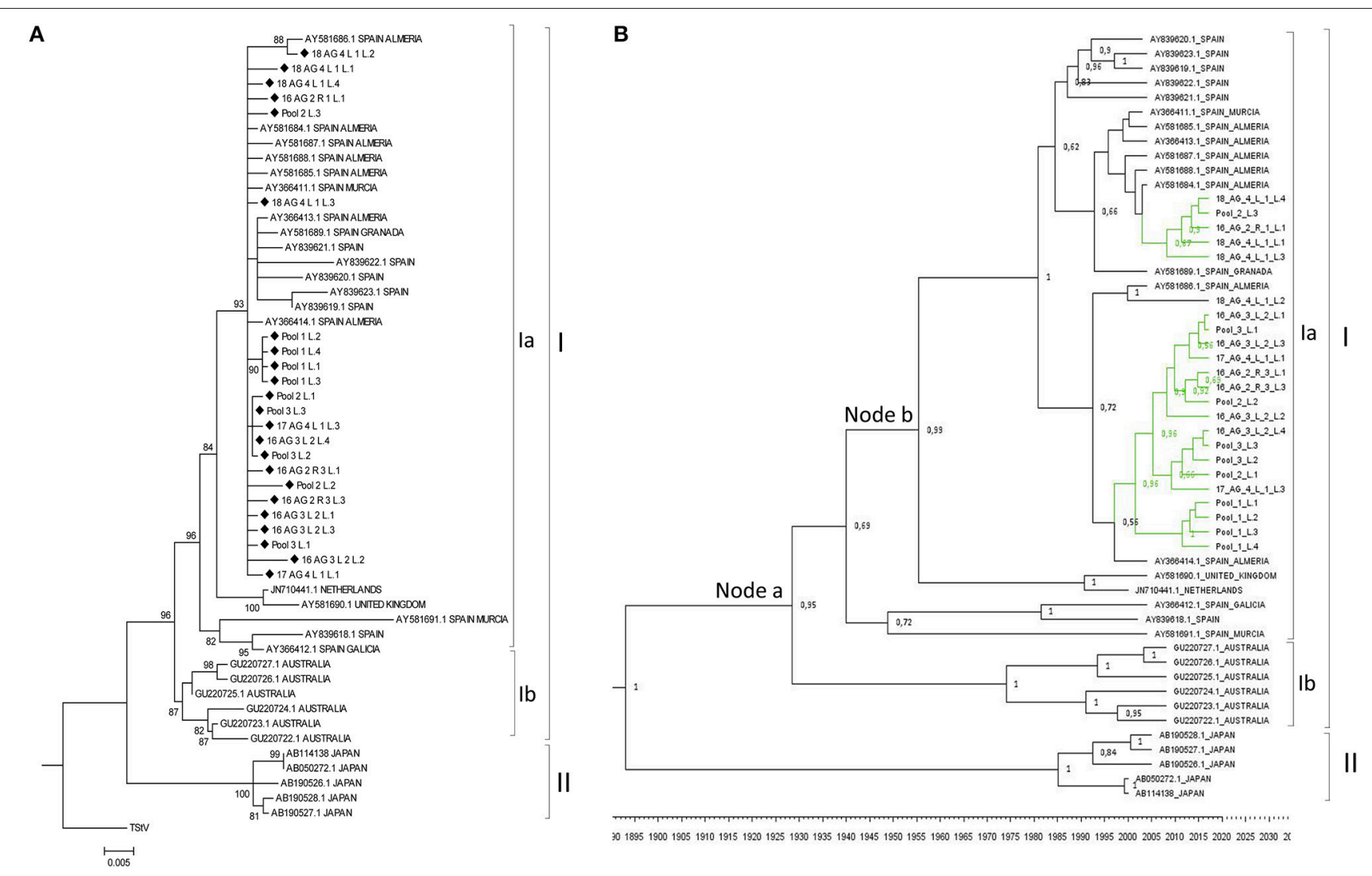

FIGURE 5 | (A) Phylogenetic relationships among the complete CP nucleotide sequences of LBVaV isolates. The evolutionary history was inferred using the Maximum Likelihood method with 1000 bootstrap replicates, applying the Kimura-2-parameter+G model. Branch nodes with $<70 \%$ bootstrap values were collapsed. Tree including the 25 non-redundant sequences determined in this work and LBVaV sequences from Australia, Europe and Japan. The tree was rooted with tobacco stunt virus (TStV; genus Varicosavirus) CP sequence (ref AB190525.1). Sequences determined in this work are marked with diamond symbols. (B) Bayesian Maximum Clade credibility tree. Node labels correspond to posterior probability support values (values below $50 \%$ are not shown). The inferred divergence time is shown below the tree. Sequences were named according to the GenBank accession number except the sequences identified in this study (colored in green), which were named with their sequence codes (Table 1).

polarity derived from MiLBVV-RNA4 in all sample pools could be explained if the positive strand was able to form more abundant or perhaps different stable secondary structures than the negative strand due to thermodynamic reasons. vsRNAs showed a near full-coverage of the viral genomes for both MiLBVV and LBVaV (Supplementary Table 1 and Figure 2), however, the distribution of vsRNAs along the viral genomes was heterogeneous, showing peaks of vsRNA accumulation in certain regions and in both viral strands (Figure 3). Heterogeneous vsRNA distribution has been reported roughly in all plant viruses studied to date, and could be a reflection of regions that are preferentially targeted by DCL for vsRNA biogenesis, such as highly structured regions with strong secondary structure, although clear experimental evidence for this is still lacking (Donaire et al., 2009; Llave, 2010; Donaire and Ayllón, 2017).

Knowledge on the variability and genetic structure of viral populations is fundamental for the deployment of sustainable disease control strategies (García-Arenal et al., 2001). Our analyses of the MiLBVV populations indicated that isolates of three different lineages co-circulated during the epidemics in
Spain. The diversity of the sequences within each lineage was very low, while the total diversity was high. This denotes that the genetic diversity of the analyzed population was determined by the presence of these three well-differentiated lineages and not by the diversity of isolates within the lineages. On the other hand, the overall diversity of the sequences determined in this work (mean nucleotide distance $=0.059 \pm 0.005$ ) was almost as great as that determined for the set of these sequences plus those that could be downloaded from the databases $(0.068 \pm 0.005)$, which indicates that the isolates of the Spanish population mirror almost all of the diversity described for the MiLBVV species (Maccarone et al., 2010b). Likewise, in the phylogenetic analysis in which non-Spanish isolates were included, no relationship was found between the geographic origin of the sequence and its position in the phylogenetic tree, which may suggest frequent long distance movement of infective materials. The situation described for LBVaV was different. On the one hand, the diversity of the population analyzed was considerably lower than that of the MiLBVV population; essentially, the population of LBVaV analyzed in this work could be considered genetically 


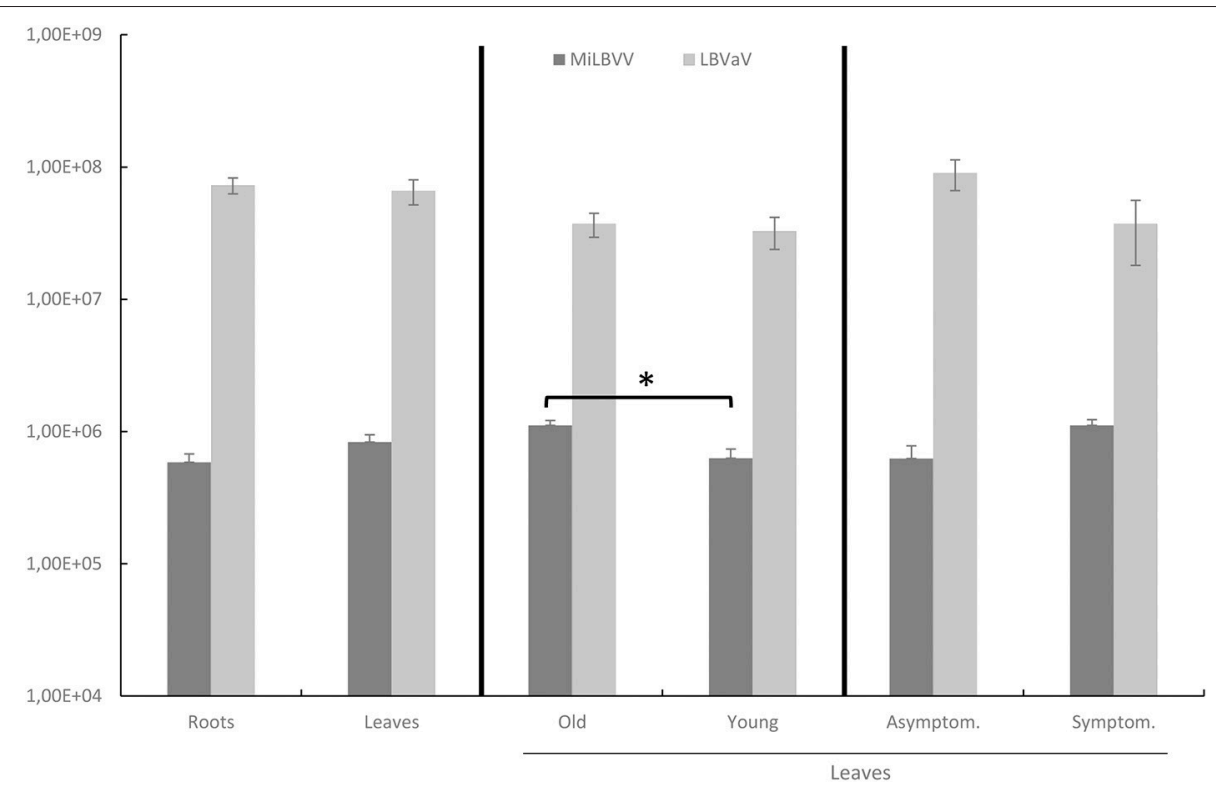

FIGURE 6 | Accumulation of viral CP RNA in tissues from different lettuce samples from affected fields. Statistical analyses were performed separately comparing the accumulation of both viruses in leaves vs. roots, old leaves vs. young leaves, and asymptomatic vs. symptomatic leaves. Data represent the mean \pm SE of each group. An asterisk indicates significant differences according to a Kruskal-Wallis's test $(p<0.05)$.

TABLE 5 | Results of qRT-PCR assays for detection of the viruses associated with LBVD in commercial lettuce seeds obtained from different providers.

\begin{tabular}{|c|c|c|c|c|}
\hline \multirow[t]{2}{*}{ Samples $^{a}$} & \multicolumn{2}{|c|}{ MiLBVV } & \multicolumn{2}{|c|}{ LBVaV } \\
\hline & SYBR Green & TaqMan & SYBR Green & TaqMan \\
\hline 17_AG_Ø_S1_Ø & + & + & + & + \\
\hline 17_AG_Ø_S2_Ø & + & + & + & + \\
\hline 17_AG_Ø_S3_Ø & - & - & + & + \\
\hline 17_AG_Ø_S4_Ø & - & - & + & + \\
\hline 17_AG_Ø_S5_Ø & - & - & + & + \\
\hline 17_AG_Ø_S6_Ø & - & - & + & + \\
\hline 17_AG_Ø_S7_Ø & - & - & - & - \\
\hline 17_AG_Ø_S8_Ø & - & - & - & - \\
\hline 17_AG_Ø_S9_Ø & - & - & + & + \\
\hline 17_AG_Ø_S10_Ø & - & - & - & - \\
\hline 17_AG_Ø_S11_Ø & - & - & - & - \\
\hline
\end{tabular}

aEach sample corresponds to a different variety of lettuce (1-11) and was named according to the following code: Year_Location_Plot_Tissue_Plant. $\varnothing$ indicates absence of data.

undifferentiated. In contrast, when a phylogenetic analysis was carried out including the sequences determined in this work plus others from diverse geographical origins available in databases, the existence of three main lineages that shared common geographic origins (Japan, Australia, and Europe) could be identified, in agreement with previous observations (Maccarone et al., 2010c). Thus, for LBVaV there seems to be little diversity at the regional scale, although there is differentiation at the global scale. These observations argue in favor of a limited movement of $\mathrm{LBVaV}$ infective material at the global scale, contrary to what was discussed for MiLBVV. Lastly, the greater genetic diversification of MiLBVV in the study area compared to LBVaV may suggest a presence of the first virus in the zone prior to the second one, although the Bayesian analyses that we have carried out seemed to suggest otherwise.

The primers used to detect and quantify the accumulation of MiLBVV and LBVaV in this work functioned effectively, providing conclusive results from all types of samples. With regard to the analysis of symptomatic and asymptomatic plants, our results coincided with those of other authors (Walsh, 1994; Araya et al., 2011) in the sense that asymptomatic plants could accumulate similar amounts of viruses as symptomatic plants, and that the severity of symptoms was not associated with a greater accumulation of viruses. This could have a very significant impact when eradicating infection foci and/or virus reservoirs, which would not be perceived by the farmer unless the symptoms were manifested or specific detection of the viruses was carried out with methods such as those used in this work. Thus far, the factors responsible for the expression of the LBVD symptoms are not well known, although the perception of symptoms in the fields is much more frequent in cool periods and short days. Likewise, our results on the accumulation of viruses in infected plants essentially coincided with those of Navarro et al. (2004), although these authors described a greater accumulation of both viruses in old vs. young leaves and roots that our results were not able to reproduce; perhaps this difference was due to the different methods used for detection, in our case more sensitive and probably more appropriate for the quantification of viral accumulation. Another aspect coinciding with the work of Navarro et al. (2004) consisted of the detection of consistently higher accumulation levels for $\mathrm{LVBaV}$ than for MiLBVV; this aspect may have had an impact on the characterization of 
the etiology of the disease (Roggero et al., 2003; Sasaya et al., 2008) as the detection of MiLBVV requires a higher sensitivity than that required for $\mathrm{LBVaV}$. Also, the distribution of viruses along with the sampling of infected plants may have played an important role in this regard. In summary, our work points to a consistent association of both viruses with LBVD in Murcia fields. On the other hand, our results of virus detection in seeds suggested the possibility of their transmission through seeds. The literature regarding the presence of both viruses in seeds is very scarce. Maccarone (2009) detected the presence of LBVaV and MiLBVV by RT-PCR in extracts of seeds from lettuce plants affected by LBVD. In our work, the presence of both viruses was detected in commercial seed lots from different brands. In all the batches analyzed, virus titer, both for MiLBVV and for LBVaV, was very low, so if there was seed transmission, the number of infected seedlings would probably be very low. LBVaV was detected more frequently than MiLBVV in the analyzed seeds, which would suggest a higher probability of seed transmission for LBVaV than for MiLBVV, although our phylogenetic analyses suggest otherwise. In any case, the detection of both viruses in commercial seed lots is an important finding and precautionary measures should be adopted, in addition to carrying out further studies to determine if the presence of the viruses in the seeds can result in the infection of the resulting seedlings.

\section{AUTHOR CONTRIBUTIONS}

MA, MJ, MS-P, YH, and AB-V designed and planned the research. AB-V performed the experiments, carried out statistical analyses and was involved in data interpretation and manuscript writing with MA and LD. LD was involved in the bioinformatic analyses of viral small RNA. CT and CG-A were involved in the diversity and phylogenetic analyses. $\mathrm{YH}$ coordinated and managed research activities.

\section{FUNDING}

CG-A was recipient of grant PTQ-15-07646 from the TorresQuevedo program (Ministry of Economy, Industry and Competitiveness; Spain) and CT of fellowship DI-14-06825 from the Industrial Doctoral program (Ministry of Economy, Industry and Competitiveness, Spain).

\section{REFERENCES}

Araya, C., Peña, E., Salazar, E., Román, L., Medina, C., and Mora, R. (2011). Symptom severity and viral protein or RNA accumulation in lettuce affected by big-vein disease. Chil. J. Agric. Res. 71, 63-72. doi: 10.4067/S0718-58392011000100008

Bouckaert, R., Heled, J., Kühnert, D., Vaughan, T. G., Wu, C. H., Xie, D., et al. (2014). Beast2: a software platform for Bayesian evolutionary analysis. PLoS Comput. Biol. 10:4. doi: 10.1371/journal.pcbi.1003537

Campbell, R. N. (1985). Longevity of Olpidium brassicae in air-dry soil and the persistence of the lettuce big-vein agent. Canad. J. Bot. 63, 2288-2289. doi: $10.1139 / \mathrm{b} 85-326$

\section{ACKNOWLEDGMENTS}

We thank Antonia Fernández, Ángeles Lozano, and Karen Covey (Frutas y Hortalizas del Sureste S.L., Murcia, Spain) for their support during field surveys, Juan S. Navarro (Abiopep S.L., Murcia, Spain) for his technical assistance and Mario Fon (mariogfon@gmail.com) for editorial assistance.

\section{SUPPLEMENTARY MATERIAL}

The Supplementary Material for this article can be found online at: https://www.frontiersin.org/articles/10.3389/fmicb. 2018.03188/full\#supplementary-material

\section{Supplementary Figure 1 | Phylogenetic relationships among the complete CP} nucleotide sequences of MiLBW isolates, including seed sequences (marked in red). The evolutionary history was inferred by Maximum Likelihood with 1000 bootstrap replicates, with the application of the Tamura-Nei+G model. Branch nodes with $<70 \%$ bootstrap values were collapsed. (A) Tree constructed with the 26 non-sequences obtained in this work and rooted with blueberry mosaic associated virus (ref. NC 036634.1) CP sequence. (B) Tree constructed including additional MiLBW from the databases. (C) Bayesian Maximum Clade credibility tree. Node labels correspond to posterior probability support values (values below $50 \%$ are not shown). The inferred divergence time is shown below the tree.

Sequences were named according to the GenBank accession number except for the sequences identified in this study (colored in green), which were named with their sequence codes (Table 1).

Supplementary Figure 2 | Phylogenetic relationships among the complete CP nucleotide sequences of LBVaV isolates, including sequences from seeds (marked in red). The evolutionary history was inferred using the Maximum Likelihood method with 1000 bootstrap replicates, with the application of the Kimura-2-parameter $+\mathrm{G}$ model. Branch nodes with $<70 \%$ bootstrap values were collapsed. (A) Tree including the 38 non-redundant sequences determined in this work and LBVaV sequences from Australia, Europe and Japan. It was rooted with tobacco stunt virus (TStV; genus Varicosavirus) CP gene (ref AB190525.1). (B) Bayesian Maximum Clade credibility tree. Node labels correspond to posterior probability support values (values below $50 \%$ are not shown). The inferred divergence time is shown below the tree. Sequences were named according to the GenBank accession number except for the sequences identified in this study (colored in green), which were named with their sequence codes (Table 1).

Supplementary Figure 3 | Accumulation of viral CP RNA in pools 1-3 (see Table 1). Data represent the mean \pm SE for each pool.

Supplementary Table 1 | Coverage and sequencing depth of sRNAs mapping to viruses identified by the VirusDetect online tool.

Supplementary Table 2 | Percentage of identity of viral contigs assembled by VirusDetect against CP sequences of LBVD-associated viruses collected from NCBI.

Supplementary Table 3 | List of MiLBW and LBVaV sequences from NCBI used for the phylogenetic analysis.

Campbell, R. N., and Fry, P. R. (1966). The nature of the associations between Olpidium brassicae and lettuce big-vein and tobacco necrosis viruses. Virology 29, 222-233. doi: 10.1016/0042-6822(66)90028-6

Donaire, L., and Ayllón, M. A. (2017). Deep sequencing of mycovirusderived small RNAs from Botrytis species. Mol. Plant Pathol. 8, 1127-1137. doi: 10.1111/mpp.12466

Donaire, L., Barajas, D., Martinez-Garcia, B., Martinez-Priego, L., Pagan, I., and Llave, C. (2008). Structural and genetic requirements for the biogenesis of tobacco rattle virus-derived small interfering RNAs. J. Virol. 82, 5167-5177. doi: 10.1128/JVI.00272-08

Donaire, L., Wang, Y., Gonzalez-Ibeas, D., Mayer, K. F., Aranda, M. A., and Llave, C. (2009). Deep-sequencing of plant viral small RNAs reveals 
effective and widespread targeting of viral genomes. Virology 392, 203-214. doi: 10.1016/j.virol.2009.07.005

Felsenstein, J. (1981). Evolutionary trees from DNA sequences: a maximum likelihood approach. J. Mol. Evol. 17, 368-376. doi: 10.1007/BF01734359

García-Arenal, F., Fraile, A., and Malpica, J. M. (2001). Variability and genetic structure of plant virus populations. Annu. Rev. Phytopathol. 39, 157-186. doi: 10.1146/annurev.phyto.39.1.157

Hartwright, L. M., Hunter, P. J., and Walsh, J. A. (2010). A comparison of Olpidium isolates from a range of host plants using internal transcribed spacer sequence analysis and host range studies. Fungal Biol. 114, 26-33. doi: 10.1016/j.mycres.2009.09.008

Jagger, I. C., and Chandler, N. (1934). Big vein, a disease of lettuce. Phytopathology $24,1253-1256$.

Kaldis, A., Berbati, M., Melita, O., Reppa, C., Holeva, M., Otten, P., et al. (2018). Exogenously applied dsRNA molecules deriving from the Zucchini yellow mosaic virus (ZYMV) genome move systemically and protect cucurbits against ZYMV. Mol. Plant Pathol. 19, 883-895. doi: 10.1111/mpp.12572

Kim, V. N. (2008). Sorting out small RNAs. Cell 133, 25-26. doi: 10.1016/j.cell.2008.03.015

Kimura, M. (1980). A simple method for estimating evolutionary rate of base substitutions through comparative studies of nucleotide sequences. J. Mol. Evol. 16, 111-120. doi: 10.1007/BF01731581

King, A. M. Q., Adams, M. J., Carsten, E. B., and Lefkowitz, E. J. (2012). Virus Taxonomy: Classification and Nomenclature of Viruses. Ninth Report of the International Committee on Taxonomy of Viruses (London: Elsevier).

Kumar, S., Stecher, G., and Tamura, K. (2016). MEGA7: molecular evolutionary genetics analysis Version 7.0 for bigger datasets. Mol. Biol. Evol. 33, 1870-1874. doi: 10.1093/molbev/msw054

Kuwata, S., Kubo, S., Yamashita, S., and Yoji, D. (1983). Rod-shaped Particles, a probable entity of lettuce big vein virus. Annu. Phytopathol. Soc. Jpn. 49, 264-251. doi: 10.3186/jjphytopath.49.246

Lan, Y., Li, Y., Zhiguo, E., Sun, F., Du, L., and Xu, Q. (2018). Identification of virusderived siRNAs and their targets in RBSDV-infected rice by deep sequencing. J. Basic Microbiol. 58, 227-237. doi: 10.1002/jobm.201700325

Langmead, B., Trapnell, C., Pop, M., and Salzberg, S. L. (2009). Ultrafast and memory-efficient alignment of short DNA sequences to the human genome. Genome Biol. 10:R25. doi: 10.1186/gb-2009-10-3-r25

Li, H., and Durbin, R. (2009). Fast and accurate short read alignment with Burrows-Wheeler transform. Bioinformatics 25, 1754-1760. doi: 10.1093/bioinformatics/btp324

Li, L., Andika, I. B., Xu, Y., Zhang, Y., Xin, X., Hu, L., et al. (2017). Differential characteristics of viral siRNAs between leaves and roots of wheat plants naturally infected with wheat yellow mosaic virus, a soil-borne virus. Front. Microbiol. 8:1802. doi: 10.3389/fmicb.2017.01802

Llave, C. (2010). Virus-derived small interfering RNAs at the core of plant-virus interactions. Trends Plant Sci. 15, 701-707. doi: 10.1016/j.tplants.2010.09.001

Lot, H., Campbell, R. N., Souche, S., Milne, R. G., and Roggero, P. (2002). Transmission by Olpidium brassicae of Mirafiori lettuce virus and lettuce bigvein virus, and their roles in lettuce big-vein etiology. Phytopathology 92, 288-293. doi: 10.1094/PHYTO.2002.92.3.288

Maccarone, L. D. (2009). Molecular Genetic Characterisation of Mirafiori Lettuce Big-Vein Virus and Lettuce Big-Vein Associated Virus and Their Vector Olpidium virulentus Associated with Lettuce Big-Vein Disease and the Determination of Their Inoculum Sources in Western Australia. Ph.D. thesis, University of Western Australia, Perth, WA.

Maccarone, L. D. (2013). Relationships between the pathogen Olpidium virulentus and viruses associated with lettuce big-vein disease. Plant Dis. 97, 700-707. doi: 10.1094/PDIS-10-12-0979-FE

Maccarone, L. D., Barbetti, M. J., Sivasithamparam, K., and Jones, R. A. C. (2010a). Molecular genetic characterization of Olpidium virulentus isolates associated with big-vein diseased lettuce plants. Plant Dis. 94, 563-569. doi: 10.1094/PDIS-94-5-0563

Maccarone, L. D., Barbetti, M. J., Sivasithamparam, K., and Jones, R. A. C. (2010b). Comparison of the coat protein genes of Mirafiori lettuce big-vein virus isolates from Australia with those of isolates from other continents. Arch. Virol. 155, 1519-1522. doi: 10.1007/s00705-010-0740-y

Maccarone, L. D., Barbetti, M. J., Sivasithamparam, K., and Jones, R. A. C. (2010c). Comparison of the coat protein genes of Lettuce big-vein associated virus isolates from Australia with those of isolates from other continents. Arch. Virol. 155, 765-770. doi: 10.1007/s00705-010-0641-0

Momonoi, K., Mori, M., Matsuura, K., Moriwaki, J., and Morikawa, T. (2015). Quantification of Mirafiori lettuce big-vein virus and its vector, Olpidium virulentus, from soil using real-time PCR. Plant Pathol. 64, 825-830. doi: 10.1111/ppa.12333

Moreno, A., De Blas, C., Biurrun, R., Nebreda, M., Palacios, I., Duque, M., et al. (2004). The incidence and distribution of viruses infecting lettuce, cultivated Brassica and associated natural vegetation in Spain. Ann. appl. Biol. 144, 339-346. doi: 10.1111/j.1744-7348.2004.tb00349.x

Moreno, A., and Fereres, A. (2012). Virus diseases in lettuce in the Mediterranean Basin. Adv. Virus Res. 84, 247-288. doi: 10.1016/B978-0-12-394314-9.00007-5

Navarro, J. A., Botella, F., Marhuenda, A., Sastre, P., Sánchez-Pina, M. A., and Pallas, V. (2005). Identification and partial characterisation of Lettuce bigvein associated virus and Mirafiori lettuce big-vein virus in common weeds found amongst Spanish lettuce crops and their role in lettuce big-vein disease transmission. Eur. J. Plant Pathol. 113, 25-34. doi: 10.1007/s10658-005-8916-0

Navarro, J. A., Botella, F., Maruhenda, A., Sastre, P., Sánchez-Pina, M. A., and Pallas, V. (2004). Comparative infection progress analysis of lettuce big-vein virus and mirafiori lettuce virus in lettuce crops by developed molecular diagnosis techniques. Phytopathology 94, 470-477. doi: 10.1094/PHYTO.2004.94.5.470

Nei, M., and Gojobori, T. (1986). Simple methods for estimating the numbers of synonymous and nonsynonymous nucleotide substitutions. Mol. Biol. Evol. 3, $418-426$.

Nei, M., Xu, P., and Glazko, G. (2001). Estimation of divergence times from multiprotein sequences for a few mammalian species and several distantly related organisms. Proc. Natl. Acad. Sci. U.S.A. 98, 2497-2502. doi: 10.1073/pnas.051611498

Parameswaran, P., Sklan, E., Wilkins, C., Burgon, T., Samuel, M. A., Lu, R., et al. (2010). Six RNA viruses and forty-one hosts: viral small RNAs and modulation of small RNA repertoires in vertebrate and invertebrate systems. PLoS Pathog. 6:e1000764. doi: 10.1371/journal.ppat.1000764

Reyes-Chin-Wo, S., Wang, Z., Yang, X., Kozik, A., Arikit, S., and Song, C. (2017). Genome assembly with in vitro proximity ligation data and wholegenome triplication in lettuce. Nat. Commun. 8:14953. doi: 10.1038/ncomms 14953

Roggero, P., Ciuffo, M., Vaira, A. M., Accotto, G. P., Masenga, V., and Milne, R. G. (2000). An ophiovirus isolated from lettuce with big-vein symptoms. Arch. Virol. 145, 2629-2642. doi: 10.1007/s007050070012

Roggero, P., Lot, H., Souche, S., Lenzi, R., and Milne, R. G. (2003). Occurrence of Mirafiori lettuce virus and Lettuce big-vein virus in relation to development of big-vein symptoms in lettuce crops. Eur. J. Plant Pathol. 109, 261-267. doi: 10.1023/A:1023060830841

Santala, J., Valkonen, J. P. T., and Carr, J. P. (2018). Sensitivity of small RNA-based detection of plant viruses. Front. Microbiol. 9:939. doi: 10.3389/fmicb.2018.00939

Sasaya, T., Fujii, H., Ishikawa, K., and Koganezawa, H. (2008). Further evidence of Mirafiori lettuce big-vein virus but not of Lettuce big-vein associated virus with big-vein disease in lettuce. Phytopathology 98, 464-468. doi: 10.1094/PHYTO-98-4-0464

Sasaya, T., Ishikawa, K., and Koganezawa, H. (2002). The nucleotide sequence of RNA1 of Lettuce big-vein virus, genus Varicosavirus, reveals its relation to nonsegmented negative-strand RNA viruses. Virology 297, 289-297. doi: 10.1006/viro.2002.1420

Sasaya, T., Kusaba, S., Ishikawa, K., and Koganezawa, H. (2004). Nucleotide sequence of RNA2 of Lettuce big-vein virus and evidence for a possible transcription termination/initiation strategy similar to that of rhabdoviruses. J. Gen. Virol. 85, 2709-2717. doi: 10.1099/vir.0.80061-0

Seguin, J., Otten, P., Baerlocher, L., Farinelli, L., and Pooggin, M. M. (2014). MISIS: a bioinformatics tool to view and analyze maps of small RNAs derived from viruses and genomic loci generating multiple small RNAs. J. Virol. Methods 195, 120-122. doi: 10.1016/j.jviromet.2013.10.013

Sievers, F., and Higgins, D. G. (2014). Clustal omega. Curr. Protoc. Bioinforma. 48, 3.13. 1-16. doi: 10.1002/0471250953.bi0313s48

Tamura, K. (1992). Estimation of the number of nucleotide substitutions when there are strong transition-transversion and G+ C-content biases. Mol. Biol. Evol. 9, 678-687. 
Tamura, K., and Nei, M. (1993). Estimation of the number of nucleotide substitutions in the control region of mitochondrial DNA in humans and chimpanzees. Mol. Biol. Evol. 10, 512-526.

Thompson, J. D., Gibson, T. J., Plewniak, F., Jeanmougin, F., and Higgins, D. G. (1997). The CLUSTAL X windows interface: flexible strategies for multiple sequence alignment aided by quality analysis tools. Nucleic Acids Res. 25, 4876-4882. doi: 10.1093/nar/25. 24.4876

Walsh, J. A. (1994). Effects of some biotic and abiotic factors on symptom expression of lettuce big-vein virus in lettuce (Lactuca sativa). J. Hortic. Sci. 69, 21-28. doi: 10.1080/14620316.1994.11515244

Xu, D., and Zhou, G. (2017). Characteristics of siRNAs derived from Southern rice black-streaked dwarf virus in infected rice and their potential role in host gene regulation. Virol. J. 14, 1-16. doi: 10.1186/s12985-0170699-3

Zaagueri, T., Miozzi, L., Mnari-Hattab, M., Noris, E., Accotto, G. P., and Vaira, A. M. (2017). Deep sequencing data and infectivity assays indicate that chickpea chlorotic dwarf virus is the etiological agent of the "Hard Fruit Syndrome" of watermelon. Viruses 9:311. doi: 10.3390/v91 10311

Zheng, Y., Gao, S., Padmanabhan, C., Li, R., Galvez, M., Gutierrez, D., et al. (2017). VirusDetect: an automated pipeline for efficient virus discovery using deep sequencing of small RNAs. Virology 500, 130-138. doi: $10.1016 /$ j.virol.2016.10.017

Conflict of Interest Statement: The authors declare that the research was conducted in the absence of any commercial or financial relationships that could be construed as a potential conflict of interest.

Copyright (C) 2018 Bernal-Vicente, Donaire, Torre, Gómez-Aix, Sánchez-Pina, Juarez, Hernando and Aranda. This is an open-access article distributed under the terms of the Creative Commons Attribution License (CC BY). The use, distribution or reproduction in other forums is permitted, provided the original author(s) and the copyright owner(s) are credited and that the original publication in this journal is cited, in accordance with accepted academic practice. No use, distribution or reproduction is permitted which does not comply with these terms. 